\title{
I. Grundlagen und Traditionen
}

\author{
1. Schmittleins Werdegang im Kontext \\ französischer Germanistik, auswärtiger Kulturpolitik \\ und Schulreformbestrebungen bis 1945
}

18. April 1945. Für die Bewohner des nördlichen Schwarzwaldés nahm der Zweite Weltkrieg in diesen Tagen ein schreckensreiches Ende. Während Freudenstadt in Flammen stand und um Nagold noch erbittert gekämpft wurde, waren französische Panzer bereits in südlicher und östlicher Richtung weitergerollt, versprengte Reste der Wehrmacht vor sich hertreibend. Unter den Offizieren der 2. Marokkanischen Infanteriedivision, die an diesem strahlenden Frühlingstag Altensteig erreichte, befand sich der Lieutenant-colonel Raymond Schmittlein, den alsbald ein Telegramm ins Hauptquartier des Generals de Lattre de Tassigny nach Karlstuhe berief. Der Befehlshaber der 1. Französischen Armee eröffnete ihm, daß höhere Aufgaben als der Dienst in der Truppe auf ihn warteten ${ }^{1}$. Schmittlein zeigte sich von dieser ehrenvollen Ankündigung wenig begeistert. Im Juli 1944 hatte er sich von einem zivilen Posten im Kabinett de Gaulles in Algier suspendieren lassen, um aktiv kämpfend an der Befreiung Frankreichs teilzunehmen. Nach einem kurzen Einsatz in Italien war er im August bei der Landung französischer und alliierter Truppen an der Provenceküste dabeigewesen und hatte in Aix erstmals nach viereinhalb Jahren seine Frau und seine beiden Kinder wiedergesehen, bevor die Einheit weiter nach Norden vorgestoßen war. Im November hatte er sich bei der Rückeroberung Belforts als kühner Stratege ausgewiesen, das Angebot de Lattres, ihn in seinen Stab zu holen, jedoch abgelehnt ${ }^{2}$. Nun aber, nachdem die Deutschen endgültig aus Frankreich vertrieben waren, französische Soldaten den Rhein überschritten hatten, der alliierte Sieg offenkundig kurz bevorstand, wurde Schmittlein von der Front abberufen.

Weisungsgemäß reiste der Oberstleutnant in den ersten Maitagen nach Paris, wo er von Erziehungsminister Capitant empfangen wurde und erfuhr, daß er als dessen Repräsentant in der Militärverwaltung für das französisch besetzte Deutschland vorgesehen war. Seine Aufgabe: das Unterrichtswesen zu reorganisieren und zu kontrollieren, die Jugend zu überwachen, also die Rolle eines rééducateur de la jeunesse allemande zu übernehmen. Hinsichtlich der Mittel sollte er Phantasie walten lassen; von Personal, Räumlichkeiten, Material oder wenigstens von Direktiven war zu diesem Zeitpunkt noch keine Rede ${ }^{3}$. Ein Kabinettsbeschluß der Provisori-

\footnotetext{
1 Vgl. Schmittlein, Souvenirs; gefunden in: AOFA, AC 31,1.

2 Diese Episode schildert Schmittlein, La Nationale 83.

${ }^{3}$ Vgl. Schmittlein, Souvenirs. Aus einem Schreiben Capitants an General Koeltz vom 26.6.1945 geht hervor, daß der Erziehungsminister bereits am 4.4. die vorgesehene Ernennung Schmittleins bekanntgegeben hatte; in: AOFA, AC 65,2, No. 1294.
} 
schen Regierung de Gaulle vom 29. Juni 1945 machte Schmittleins Ernennung endgültig ${ }^{4}$.

Wer war dieser Mann, der scheinbar so überraschend vom kampfbegeisterten Offizier zu einer Art Umerziehungsminister für Französisch-Südwestdeutschland avancierte?

Raymond Schmittlein kam 1904 im nordfranzösischen Roubaix zur Welt ${ }^{5}$. Er war das sechste Kind eines elsässischen, nach 1871 in Mainz aufgewachsenen, in Deutschland und Sankt Petersburg ausgebildeten Textilingenieurs und dessen elsāssischer Frau. Als praktizierende Christen schickten die Eltem Raymond auf das katholische Collège in Roubaix ${ }^{6}$. Nach dem Abitur nahm er - seit dem elften Lebensjahr Vollwaise und mittellos - in Paris das Studium auf und belegte zunächst Literaturwissenschaft, Jura, Medizin und orientalische Sprachen ${ }^{7} .1924$ meldete er sich freiwillig zum Militärdienst und kam zu einem bei Mainz stationierten nordafrikanischen Schützenregiment der französischen Rheinarmee - in ihren Reihen diente zur selben Zeit auch der sechs Jahre ältere Leutnant Pierre-Marie Koenig ${ }^{8}$ - , wo er sich nach einiger Zeit als Bester für die Militärakademie in Saint-Cyr qualifizierte. Diese verließ er Anfang 1925 als Reserveleutnant, um sich zunächst nach Algerien zu verpflichten und dann im französischen Protektorat Marokko an der Niederschlagung der aufständischen Rif-Kabylen teilzunehmen ${ }^{9}$. Eine schwere Verwundung hinderte den jungen Schmittlein daran, endgültig die Militärlaufbahn einzuschlagen und damit in die Fußstapfen mehrerer Generationen seiner Vorfahren zu treten. So kehrte er 1926 als Student nach Paris zurück und belegte zunächst in einem Seminar der Mission Etrangère einige Semester Theologie (vor allem Exegese und orientalische Sprachen) ${ }^{\mathbf{1 0}}$, bevor er sich endgültig der Literaturwissenschaft an der Sorbonne zuwandte, wo er 1931 die Licence ès lettres erwarb. Anschließend ging er an die Friedrich-Wilhelm-Universität zu Berlin. Hier, in der politisch aufgewühlten Reichshauptstadt, lernte er Gerta Eichholz kennen, die er 1932 heiratete $^{11}$. Im selben Jahr bestand er mit einer Prüfungsklausur über Martin Lu-

${ }^{4}$ MAE, Y/433, fol. 49 f., Joxe an das Außenministerium am 3.7.1945. Manns, Höchst persönliche Erinnerungen, S. $52 \mathrm{f}$., nennt als Datum der Emennung durch den Ministerrat den 16.6.1945.

3 Die Angaben zu Schmittleins Werdegang stützen sich, wenn nicht anders angegeben, auf: [Anonym,] Raymond Schmittlein; Delcroix, Un destin; Georges Schoulers Nekrolog, in: Bulletin de la Société Belfortaine d'Emulation 70 (1978), S. 15 f.; Schoulers maschinenschriftliches Manuskript zu Schmittleins Werdegang vom Oktober 1982; alle in: ADTB. Manns konnte sich auf das von Schmittleins Sohn zur Verfügung gestellte „Familienarchiv“ (Aufzeichnungen eines älteren Bruders und eines Vetters sowie Berichte der Witwe) stützen. Vgl. ferner Steil-Beuerle, Erinnerungen, S. 195f.; Marquants biographische Skizze in: Heinemann (Hrsg.), Hochschuloffiziere, S. $21 \mathrm{ff}$; einige wichtige Daten auch in Who's Who in France, 1957/58, S. 2063, bzw. 1969, S. 1318. Keine sachdienlichen Aufschlüsse erlaubt DreyfusSchmidt, Raymond Schmittlein.

6 Vgl. Manns, ebenda, S. $25 \mathrm{f}$.

7 Vgl. [Anonym,] Raymond Schmittlein, S. 6.

8 Vgl. Who's Who in France, 1957/58, S. 1306.

9 Zur Bedeutung des Rifkrieges für die Politisierung und Polarisierung junger französischer Intellektueller der „génération de 1905“ vgl. Trebitsch, Le groupe „Philosophies“, S. 33.

10 Vgl. Manns, ebenda, S. 27.

11 Vgl. ebenda. Daß Gerta Schmittlein, geb. Eichholz, Deutsche war (in Mülheim/Ruhr geboren, 
ther ${ }^{12}$ die schwierige Agrégation d'allemand, die ihm die höchste Stufe der Gymnasiallehrerlaufbahn, aber auch die Aussicht auf eine Hochschulkarriere eröffnete.

Die französische Germanistik der Zwischenkriegszeit

Schmittlein, auf den die Generationsbeschreibung des etwa gleichaltrigen Bertrand de Jouvenel ebenfalls zutrifft ${ }^{13}$, studierte zu einer Zeit, als innerhalb der französischen Germanistik eine kleine Zahl namhafter Professoren tonangebend und besonders einflußreich waren. $\mathrm{Zu}$ ihnen zählten die „Altmeister" Charles Andler und Henri Lichtenberger, die ebenso wie ihre etwas jüngeren Kollegen Ernest Tonnelat und Robert d'Harcourt an Pariser Hochschulinstituten wirkten, sowie (zunächst in Straßburg) Jean-Edouard Spenlé und Edmond Vermeil, der 1934 die Nachfolge seines verstorbenen Lehrers Andler an der Sorbonne übernahm. Zu den Hauptmerkmalen dieser akademischen Zunft, wie sie seit der Jahrhundertwende in Frankreich betrieben wurde, gehörte einerseits die Abkehr von einer rein linguistischen, literatur- oder geistesgeschichtlichen Beschäftigung mit dem Nachbarland zugunsten der Einbeziehung politischer, wirtschaftlicher und sozialer Faktoren der neueren deutschen Geschichte; andererseits - und damit zusammenhängend - der Anspruch, aus den gewonnenen Einsichten auch politische Lehren für die Gegenwart zu ziehen ${ }^{14}$. Lichtenberger setzte mit seinem 1907 erschienenen Buch „L'Allemagne moderne“ einen Markstein für die in der Folge zahlreich unternommenen essais d'explication. Faszination und zugleich tiefe Beunruhigung werden hierin spürbar, sobald das Bildnis eines Deutschlands der Kultur, der Dichter und Denker hinter dem des ökonomisch und militärisch mächtigen, nach Hegemonie strebenden Reiches verschwindet und die These aufscheint, daß sich Deutschlands Modernisierung auf einem „Sonderweg“ vollziehe, der es zwangsläufig den westlichen Demokratien entfremden müsse ${ }^{15}$. Spiegelt sich hierin auch der „Mythos vom zweierlei Deutschland“16 wider, die vielbeschworene Antinomie von Preußen und Süddeutschland, von Macht und Geist, die im Gefolge der traumatischen Niederlage von 1870/71 in Frankreich schnell Verbreitung gefunden hatte, so wollte Lichtenberger doch nichts von der „Entdeckung des 'Boche ${ }^{\text {'«17 }}$ wissen, mit der ein Teil des intellektuellen Frankreich seit etwa 1890 seine Desillusionierung über das vermeintlich ,gute Deutschland“ rationalisierte, nunmehr unterstellend, daß Machtstreben und Herrschsucht im „deutschen Wesen“ angelegt seien ${ }^{18}$. Zwischen diesen beiden Polen - hier Bewunderung für das weltoffene, humanistisch gebildete Deutschland der Vergangenheit, dort Ablehnung des nationalistischen, waffenstarren-

\section{Fortsetzung Fußnote von Seite 20}

in Königsberg und Berlin aufgewachsen), wird in den französischen Publikationen ebenso übergangen wie das anfängliche Theologiestudium ihres Mannes.

12 Dieses nebensächlich-symboltrāchtige Detail bei Manns, ebenda, S. 30.

$13 \mathrm{Vgl}$. de Jouvenel, Un voyageur, S. 76: Seine Altersklasse sei gerade noch zu jung gewesen, um am Krieg [von 1914-18] teilzunehmen, aber schon alt genug, um seine Schicksalsschläge mitzuerleben, seine Schrecken zu begreifen und von den Verlusten betroffen zu sein, die er in den Familien verursachte.

${ }^{14}$ Vgl. Merlio, L'image, S. 67 f.; Le Rider, La Revue d'Allemagne, S. 363.

15 Vgl. Merlio, ebenda, S. 68.

16 Leiner, Deutschlandbild, S. $154 \mathrm{ff}$.

17 Ebenda, S. $181 \mathrm{ff}$.

18 Vgl. hierzu auch Digeon, La crise allemande. 
den Nachbarstaates der Gegenwart - oszillierte auch die Einleitung Andlers zu seiner vierbändigen „Collection de documents sur le pangermanisme“, die in den Kriegsjahren 1915 bis 1918 erschien. Neben dem Dämon des deutschen Einheits- und Expansionsstrebens seit dem frühen 19. Jahrhundert war es vor allem die Chimäre des Preußentums, die ihn und andere französische Beobachter - spätestens seit Lévy-Bruhls 1890 veröffentlichtem Essai „L'Allemagne depuis Leibniz“ - peinigte ${ }^{19}$. Wie den pangermanisme sahen sie den prussianisme, die sich seit Friedrich II. abzeichnende Vormachtstellung des preußischen „Krieger- und Räuberstaates“, als Widerpart eines anderen, besseren Deutschlands. Für Andler (in der Einleitung zur „Collection“) wie später seinen Schüler Vermeil lag die Bedrohlichkeit des zeitgenössischen Nachbarn im wesentlichen darin, daß dieser seine nationale Einigung und seinen weltpolitischen Aufstieg unter Preußens Führung, also auf der Grundlage von lutherischem Glaubensbekenntnis und friderizianischem Machtkalkül, vollzogen habe. „Verpreußung“ und „Modernisierung“ seien Hand in Hand gegangen und hätten eine enorme Verarmung der geistigen wie politischen Kultur mit sich gebracht, da die „nordische Rationalität" eine rein instrumentale sei, keine aufklärerisch-humanistischen Werte impliziere und Modernisierung ohne Demokratisierung ermöglicht habe ${ }^{20}$.

Im Grunde blieben solche Argumentationsmuster mit ihren ideengeschichtlich begründeten, deterministischen Klischees dem überkommenen Bild vom romantischen Deutschland verhaftet. Allerdings hatte sich zwischenzeitlich die Idylle der Madame de Staël ${ }^{21}$ in dem Maße verkehrt, daß Vermeil später die nationalsozialistische Transformation der Republik, die „deutsche Revolution“, als „organisierte Romantik“ bezeichnete $^{22}$. Einzuräumen ist indessen, daß sich die in Frankreich gängigen Stereotypen weitgehend aus deutschen Quellen speisten: Weder der Mythos des Faustischen noch die Überhöhung „preußischer Tugenden“ oder die „Sonderweg“-These waren linksrheinische Erfindungen; allerdings wurden die ursprünglich positiven Vorzeichen mit negativen vertauscht. Dabei erlagen selbst notorisch Germanophile zeitweilig der Versuchung, in eine simplifizierende „Volkscharakter“-Kunde abzugleiten ${ }^{23}$. Vor dieser Gefahr suchte Lichtenberger, der wohl profilierteste unter jenen „germanistes médiateurs“, die in der seit Ende 1927 erscheinenden „Revue d'Allemagne“ ihr bevorzugtes Sprachrohr fanden, sein akademisches Publikum zu warnen. In einem Aufsatz zur "Psychologie der deutsch-französischen Wiederannäherung“ (1929) stellte er fest, daß für ein wirkliches geistiges Näherkommen Takt, Diskretion und die Vermeidung jeden Anscheins von Propaganda notwendig seien. „Solche Austauschbeziehungen müssen auf Gegenseitigkeit angelegt sein; einseitige Durchdringung würde auf Ablehnung stoßen.“ Zwar vermochte Lichtenberger einer „kosmopolitischen Kultur“ nichts abzugewinnen, die „banal, indifferent, schal, farb- und ausdruckslos“ bleiben müsse; unterschiedliche nationale Ausprägungen sollten durchaus in ihrer Andersartigkeit bestehenbleiben und gegenseitig akzeptiert werden. Daraus jedoch eine kontrastierende „Volkscharakter“-Kunde abzuleiten, lehnte er entschieden ab. Ebenso verwarf

\footnotetext{
19 Vgl. Merlio, L'image, S. 69 ff.; ausführlicher ders., Les germanistes français; Leiner, Deutschlandbild, S. 188.

${ }^{20}$ Zum Gesamtkomplex vgl. Köhler, Das Ende Preußens.

${ }_{21}$ Zusammenfassend: Leiner, Deutschlandbild, S. $86 \mathrm{ff}$.

${ }^{22}$ Vermeil, Doctrinaires, S. 18. Vgl. Merlio, L'image, S. 72; Ayçoberry, La question nazie, S. 70.

${ }^{23}$ Vgl. Merlio, L'image, S. 74 und 76.
} 
er die gängigen Klischees vom Deutschland der Romantiker und Denker, der Mystiker und Musikbesessenen, vom Frankreich der Klassiker und Rhetoriker, der Positivisten und bildenden Künstler. Bei allen Differenzen gelte es zu bedenken, daß Franzosen und Deutsche nicht zwei verschiedenartige Gattungen darstellten, die zum ewigen Gegensatz verdammt seien, sondern über einen großen Fundus an Gemeinsamkeiten verfügten ${ }^{24}$. Lichtenbergers Bereitschaft, Verständnis für das Nachbarvolk aufzubringen, die Verständigung mit ihm zu suchen, zeigte sich noch im Jahre 1936, als er einmal mehr der Vorreiter unter Frankreichs Germanisten - dem „neuen Deutschland" der Nationalsozialisten eine umfassende Untersuchung widmete und hierin seinen Analysen und Prognosen einen zurückhaltend optimistischen Tenor gab ${ }^{25}$. Spätestens zu diesem Zeitpunkt erwiesen sich die „Nuancen“ in den Einschätzungen Lichtenbergers und seines jüngeren Sorbonne-Kollegen Vermeil als kaum noch überbrückbare Gegensätze.

Vermeil, der wohl am stärksten politikwissenschaftlich orientierte und politisch engagierte unter denjenigen französischen Germanisten, die sich gleichzeitig als Historiker, vor allem der Kultur- und Mentalitätsgeschichte des Nachbarlandes verstanden, hatte sich über Jahre hinweg gründlich mit der staatlichen Entwicklung des rechtsrheinischen Nachbarn beschäftigt: mit der Weimarer Verfassung und dem deutschen Demokratieverständnis (1923), dem zeitgenössischen Deutschland insgesamt (1925) und seinem Verhältnis zu den westlichen Demokratien (1931). Die hierbei gewonnenen Erkenntnisse, die Ende 1937 mit einer ideengeschichtlichen Studie über die „Doktrinäre der deutschen Revolution“ angereichert wurden, kulminierten schließlich 1939 in der großen Synthese „L'Allemagne. Essai d'explication“, dem Hauptwerk, in das Plessners später berühmt gewordener Topos von der „verspäteten Nation“ ebenso einfloß wie Rauschnings „Revolution des Nihilismus“26. Vermeil, der Wissenschaftler und politisch engagierte Zeitgenosse, der profunde Kenner deutscher Kultur und aktive Antifaschist, der calvinistische Liberale, der sich als Erbe der sozialistischen Ideen seiner Lehrer Andler und Lucien Herr $^{27}$ dem Volksfrontgedanken öffnete ${ }^{28}$, symbolisiert am deutlichsten das dialektische Spannungsverhältnis der französischen Germanistik zu ihrem Analyseobjekt. Derselbe Autor, der unter dem Eindruck der deutschen Expansionspolitik seine Variante der Kontinuitätsthese - vom Nationalsozialismus als "vulgarisiertem Pangermanismus" - darlegte und vom Nachbarland ein kulturkritisches Portrăt zeichnete, das zwar intime Vertrautheit mit dessen politischer und Geistesgeschichte verriet, dabei jedoch nicht ohne völkerpsychologische Negativklischees auskam ${ }^{29}$, erwies sich in Zeiten deutsch-französischer Wiederannäherung als

${ }^{24}$ Lichtenberger, „Psychologie du rapprochement franco-allemand“, in: RA 3 (1929), S. $769 \mathrm{ff}$., hier zitiert nach Le Rider, La Revue d'Allemagne, S. 369.

${ }^{25}$ Lichtenberger, L'Allemagne nouvelle. Vgl. hierzu Merlio, Lichtenberger, S. $376 \mathrm{ff}$.

${ }^{26}$ Vgl. Merlio, Limage, S. 75; Ayçoberry, La question nazie, S. 72; Auerbach, "Que faire“, S. 290.

${ }^{27}$ Zum freundschaftlichen Verhältnis der beiden Germanisten vgl. Andler, Vie de Lucien Herr, insbesondere die Einführung von Justinien Raymond.

${ }^{28}$ Diese Charakterisierung folgt im wesentlichen der Einschätzung von Gisselbrecht, Quelques interprétations, S. 156 und $161 \mathrm{ff}$. Vgl. auch Hostache, Le Conseil National, S. 221; Lipgens, Europa-Föderationspläne, S. 201.

${ }^{29}$ Vgl. z. B. Vermeil, L'Allemagne $\left({ }^{13} 1945\right)$, S. 419 ff.; dieselbe Einschätzung Vermeils bei Merlio, L'image, S. 80. 
ein im europäischen Interesse argumentierender Anwalt der Synthese beider Kulturkreise und bilateraler Solidarităt angesichts des angelsāchsischen Kapitalismus und des sowjetischen Bolschewismus ${ }^{30}$.

\section{Deutsch-französischer Studentenaustausch}

Mitte der 20er Jahre, in der Locarno-Ära der Außenminister Briand und Stresemann, wurde das Klima der deutsch-französischen Beziehungen vorübergehend freundlicher $^{31}$. Auch im akademischen Sektor machte sich eine gewisse Entspannung bemerkbar. Im Wintersemester 1925/26 trafen zum ersten Mal seit dem Krieg ein knappes Dutzend deutscher Studenten in Paris ein, brachen umgekehrt etwa 20 französische Jungakademiker zum Studium nach Deutschland auf ${ }^{32}$. Obwohl sich Verantwortliche auf beiden Seiten zunächst gegen die Wiederaufnahme eines solchen Austauschs sträubten - der internationale Boykott deutscher Wissenschaftler war noch in $\mathrm{Kraft}^{33}$-, schwoll der Strom deutscher Studenten ins Nachbarland schnell an. Im Herbst 1926 waren es etwa 80 in Paris, von denen einige über Äußerungen einer grassierenden Germanophobie berichteten ${ }^{34}$. Immerhin enstand Anfang 1928 im Office National des Universités et Ecoles Francaises, dem Pariser akademischen Auslandsdienst, ein Bureau des relations universitaires avec l'Allemagne et l'Autriche ${ }^{35}$; ein Jahr später nahm nahe der Sorbonne ein Centre d'Etudes franco-allemandes seine Tätigkeit als Kontaktstelle für deutsche und französische Studenten auf. An beiden Einrichtungen war Lichtenberger ebenso maßgeblich beteiligt ${ }^{36}$ wie an der „Revue d'Allema-

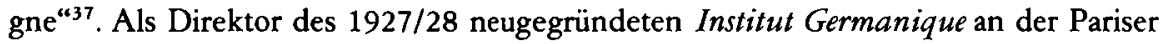
Universität ${ }^{38}$ kümmerte sich Lichtenberger auch um Studenten, die an einen Studienaufenthalt in Deutschland dachten ${ }^{39}$. Den jungen Pierre Bertaux bestärkte er beispielsweise darin, im Wintersemester $1927 / 28$ nach Berlin zu gehen ${ }^{40}$. Außerdem gehörte Lichtenberger, wie sein Straßburger Kollege Vermeil, dem Direktionskomitee

${ }^{30}$ Vgl. Vermeil, L'Allemagne contemporaine, S. 251; ders., L'Allemagne et les démocraties occidentales; ders., Les Alliés. Vermeil gehörte von Anbeginn als einer der Präsidenten dem 1948 ins Leben gerufenen Comité Français d'Echanges avec l'Allemagne Nouvelle an.

31 Vgl. Poidevin/Bariéty, Frankreich und Deutschland, S. 341 ff.; L'Huillier, Dialogues.

${ }^{32}$ Hierzu und zum Folgenden vgl. Tiemann, Jugendbeziehungen, S. 204 ff.; Richard, Aspects. Bereits Ende 1924 hatten deutsche Studenten beim französischen Konsulat in Berlin nachgefragt, ob ein Studium in Paris möglich sei; AN, 70 AJ 29, Erziehungsministerium an das AuBenministerium am 9.2.1925.

${ }^{33}$ Vgl. hierzu Schröder-Gudehus, Les scientifiques.

${ }^{34}$ Vgl. Tiemann, ebenda, S. 210 und 213 f.; als zeitgenössische Beispiele Jekel, Stipendiatenreise, S. 131; Degon, La jeunesse universitaire.

$35 \mathrm{AN}, 70 \mathrm{AJ}$ 29, Petit-Dutaillis an das Erziehungsministerium am 16.1.1928: Eine solche Gründung lasse sich wohl nicht länger aufschieben. Im März 1928 teilte das Erziehungsministerium dann in einem Rundschreiben den Akademierektoren die Gründung des Deutschlandbüros mit.

36 Ebenda, diverse Korrespondenz.

$37 \mathrm{Vgl}$. Richard, Aspects, S. $117 \mathrm{f}$.

${ }^{38}$ Vgl. Tonnelat, Das „Institut germanique“. Ende 1930 erfolgte eine Reorganisation, aus der das Institut d'Etudes Germaniques hervorging; vgl. Tiemann, Jugendbeziehungen, S. 223.

39 Vgl. ebenda, S. 218 und 223.

${ }^{40}$ Vgl. ebenda, S. 229; Bertaux, Un étudiant; ders., Zwischen Deutschland und Frankreich. 
des im Oktober 1930 in Berlin eröffneten Maison Académique Française an ${ }^{41}$. Dieses Institut unter Leitung des einflußreichen Briand-Vertrauten Professor Hesnard wollte in erster Linie qualifizierten französischen Hochschulabsolventen, die als Stipendiaten zu Forschungszwecken nach Berlin kamen, als Anlaufstelle und Wohnstätte dienen ${ }^{\mathbf{4}}$. Aufs Ganze gesehen blieb aber das Interesse französischer Studenten und Nachwuchswissenschaftler an einem Aufenthalt im Nachbarland aus verschiedenen Gründen hinter dem ihrer deutschen Kommilitonen zurück. Noch im Sommersemester 1932 stagnierte die Zahl der in Deutschland eingeschriebenen Franzosen bei etwa $30^{43}$. Diese wenigen gehörten einer „sorgfältig ausgewählten intellektuellen Elite“44 an, die überwiegend im Rahmen offizieller Austauschprogramme oder mit Stipendien der Pariser Regierung nach Deutschland gingen. Einige von ihnen begegnen uns nach 1945 auf verantwortlichen Posten der französischen Administration in Deutschland, zum Beispiel Félix Lusset, der als Chef der Mission Culturelle für die alliierten Besatzungszonen zustāndig war.

Insgesamt vollzog sich in der zweiten Hälfte der 20er Jahre bei einer aktiven Minderheit an den deutschen und französischen Universitäten ein spürbarer Einstellungswandel. Nicht mehr die mentale Isolierung des Gegners von gestern, sondern subtiles Werben für die eigenen Kulturgüter stand nun auf dem Programm. Dabei lebten bei aller Verständigungsbereitschaft auf beiden Seiten die Vorstellung eines geistigen Ringens und die Úberzeugung von der Ủberlegenheit der eigenen Nationalkultur weiter $^{45}$. Im übrigen setzte die nationalsozialistische Machtübernahme im Jahre 1933 den deutsch-französischen Studenten- und Jugendbegegnungen nicht sofort ein Ende, wenngleich sie ihren substantiellen Kern im ideologischen Interesse des neuen Regimes veränderte und auf französischer Seite auch Gegenreaktionen hervorrief. Nicht zuletzt dank der Aktivitäten des "Sohlbergkreises“ um Otto Abetz kam es bis Sommer 1938 zu mehreren bilateralen Treffen, die sich für die machtpolitischen Ziele des Hitlerstaates instrumentalisieren ließen ${ }^{46}$.

In dem geschilderten Umfeld betrieb Schmittlein von 1926 bis 1932 seine literaturwissenschaftlichen Studien in Paris und Berlin. Zwei Dekaden später, in der Rückschau des Jahres 1948, brachte er die leidvollen Erfahrungen, die seine Generation mit dem nationalsozialistischen Deutschland machte, die schmerzliche Enttäuschung über das Scheitern einer dauerhaften Aussöhnung zwischen den beiden Nachbarvölkern, in einer bitteren Bemerkung über die „sentimentalité facile“ zum Ausdruck, die die Beziehungen zwischen der deutschen und der französischen Jugend um 1930 gekenn-

41 Mitteilung des Kulturrats der französischen Botschaft in Bonn, Alain Richard, in einem Schreiben an den Verf. vom 4.2.1986.

42 Ebenda. Vgl. auch Tiemann, Jugendbeziehungen, S. 230; ders., Zweigstelle Paris, S. 291 ff.; zur Rolle Hesnards Bariéty, Artisan méconnu.

43 Vgl. Tiemann, Jugendbeziehungen, S. 210, 224 und 226. Zum Vergleich: Im Jahre 1910 waren vier französische Studenten an der Berliner Universităt eingeschrieben; vgl. Richard, Aspects, S. 111.

44 Tiemann, Jugendbeziehungen, S. 229. Nach einer undatierten, ungezeichneten Aufstellung gingen 1928/29 je sieben deutsche und französische Stipendiaten zum Studium ins Nachbarland, 1929/30 bis 1938/39 waren es jeweils zwölf bis dreizehn; in: AN, 70 AJ 29.

45 Vgl. Tiemann, Jugendbeziehungen, S. 204.

46 Vgl. Unteutsch, Sohlbergkreis, S. 79 ff.; demnächst die Tübinger Dissertation von Roland Ray über Otto Abetz. 
zeichnet und „geschwācht" habe ${ }^{47}$. Nach der Agrégation ${ }^{48}$ für das Unterrichtsfach Deutsch trat Schmittlein zunächst eine Stelle als Gymnasiallehrer an. Im selben Jahr 1932 gehörte er zu den Organisatoren einer Gedenkausstellung zum hundertsten Todestag Goethes in der Pariser Nationalbibliothek ${ }^{49}$. Wenig später schlugen ihn seine Vorgesetzten für einen Posten im Ausland vor, und so verließ das Ehepaar 1934 Frankreich, um zunächst ins litauische Kaunas (Kovno) zu ziehen. An der dortigen Universităt lehrte der Agrégé französische Sprache und Literatur, bevor er 1938 nach Lettland versetzt wurde, um die Leitung des Institut Fraņ̧ais und des Französischen Gymnasiums in Riga zu übernehmen.

\section{Frankreichs auswärtige Kulturpolitik}

Auslandsschulen und Französische Institute unterhielt die Dritte Republik in aller Welt. Den Anfang hatte die 1883 gegründete Alliance Française gemacht, eine privatrechtliche Organisation, die sich in enger Anbindung an die Pariser Außenpolitik die Erhaltung und Entwicklung des culte de la langue, de la littérature et des idées françaises bei Auslandsfranzosen und frankophilen Einheimischen im jeweiligen Gastland zum Ziel setzte ${ }^{50}$. 1902 war die Mission Lä̈que de France hinzugekommen, die zunächst besonders in Afrika und im Nahen Osten, später in den wichtigsten Hauptstädten der Welt Französische Gymnasien unterhielt ${ }^{51}$. Bis zum Ersten Weltkrieg blieb die auswärtige Kulturpolitik Frankreichs weitgehend die Domäne privater, kirchlicher und karitativer Organisationen ${ }^{52}$. Nach einem bescheidenen Anlauf des Außenministeriums im Jahre 1909, ein Mindestmaß an staatlicher Koordination solcher Aktivitäten herbeizuführen ${ }^{53}$, entstand 1920 am Quai d'Orsay der Service des CEuvres Françaises à l'Etranger, der im Dienste der „intellektuellen Expansion Frankreichs im Ausland“ wirken sollte, über die Rolle einer Mittlerorganisation allerdings nicht hinauswuchs $^{54}$. Seine vier Abteilungen widmeten sich dem Schul- und Hochschulwesen, dem Kunst- und Literaturbereich, Tourismus- und Sportfragen sowie anderen Ein-

47 AOFA, AC 68, Aufzeichnung Schmittleins für Koenig vom 24.12.1948, No. 6501/CCSG/ EDU.

48 Die Agrégation ist eine 1821 eingeführte, aus schriftlichem und mündlichem Teil bestehende Ausleseprüfung für die Fächer des höheren Lehramts. Die erfolgreichen Kandidaten, die in das Beamtenverhältnis übernommen werden, erhalten die Lehrbefugnis für die gymnasiale Oberstufe und die Vorbereitungsklassen der Elitehochschulen (Grandes Ecoles). Die Agrégés genießen großes Ansehen, haben eine geringere Lehrverpflichtung und beziehen ein höheres Gehalt als die übrigen französischen Gymnasiallehrer.

49 Vgl. Marquant, La politique cultureile, S. 114. Zum 200. Geburtstag des Dichters 1949 organisierte Schmittlein im übrigen eine Ausstellung zum Thema "Goethe und Frankreich" in der 1946 von der französischen Besatzungsmacht wiedergegründeten Universität Mainz.

so Vgl. Doka, Kulturelle Außenpolitik, S. 38; Remme/Esch, Französische Kulturpropaganda, S. $13 \mathrm{ff}$.

51 Vgl. Marès, Puissance, S. 67 und 74.

52 Vgl. Les Affaires Etrangères, S. 268f. Der kenntnisreichste und detaillierteste Uberblick zur französischen Kulturpolitik zwischen 1870 und 1914/18 in einer unveröffentlichten, 2000 Seiten umfassenden Habilitationsschrift (Paris-Sorbonne): Salon, L'action culturelle, S. $114 \mathrm{ff}$.

${ }^{33}$ In Form des zweiköpfigen Service [ab August 1910: Bureau] des Ecoles et des Euvres Françaises à l'Etranger; vgl. Les Affaires Etrangères, S. $56 \mathrm{f}$.; Young (Ed.), French Foreign Policy, S. 11; Lauren, Diplomats, S. 191.

54 Les Affaires Etrangères, S. 393; vgl. auch Outrey, Histoire, S. 724. 
richtungen auswärtiger Kulturpolitik ${ }^{55}$. Auch das Pariser Erziehungsministerium errichtete mit dem Office National des Universités et Ecoles Francaises eine eigene Auslandsdienststelle für den Lehrer-, Schüler- und Studentenaustausch, der seit 1922 teilweise in bilateralen Abkommen geregelt wurde ${ }^{56}$.

Im kulturpolitischen Budget des Quai d'Orsay erhielt in der Zwischenkriegszeit zwar das Auslandsschulwesen mit 80 bis 90 Prozent den Löwenanteil zugewiesen ${ }^{57}$, doch löste seit den frühen 20er Jahren eine „Ära der Instituts Français“ die der Auslandsschulen im engeren Sinne $a^{58}$. Bereits 1908 hatte die Universität Grenoble den ersten Schritt unternommen, als sie in Florenz ein Institut Frangais als eigene Außenstelle ins Leben rief. Neben seiner Hauptfunktion als Bindeglied zur Florentiner Hochschule widmete sich dieses Institut einem breiten Spektrum kultureller Aktivitäten: der Vermittlung von Sprachkursen und Übersetzungen, der Organisation französischer Vorträge, der Anregung von Brieffreundschaften zwischen italienischen und französischen Schülem, der Herausgabe einer Zeitschrift über bilaterale Fragen sowie der Öffentlichkeitsarbeit ${ }^{59}$. Nachdem das Pariser Parlament 1910/11 die Idee einer „universităren Außenpolitik“ aufgegriffen und finanzielle Unterstützung zugesagt hatte, entstanden noch vor dem Ersten Weltkrieg Französische Institute in London und Madrid, deren Schirmherrschaft die Universitäten Lille und Paris bzw. Toulouse und Bordeaux übernahmen, sowie in Sankt Petersburg ${ }^{60}$. Seit 1920 ergriff neben der Sorbonne zunehmend das Pariser Außenministerium die Initiative und gründete bis zum Zweiten Weltkrieg offenkundig nicht zuletzt nach geopolitischen Erwägungen 35 Auslandsinstitute vor allem in Mittel-, Ost- und Südosteuropa, aber auch in Übersee. Gleichzeitig entsandten Pariser Regierungsstellen bis Anfang der 30er Jahre über 300 französische Lehrkräfte an fast 200 ausländische Universitäten ${ }^{61}$.

Geprägt war die französische Kulturpolitik dieser Epoche von einem harten Ringen um Einflußchancen vor allem mit Deutschland, aber auch Italien und Großbritannien $^{62}$. In Berlin und Wien führte die Politik des NS-Regimes seit 1937/38 zu einem schweren Rückschlag für die Verbreitung der französischen Sprache und Kultur. In der Tschechoslowakei, wo sich die Frankophonie aufgrund der politischen Konjunktur am günstigsten entwickelt hatte, bewirkte das Münchner Abkommen vom September 1938, die Enttäuschung über das Zurückweichen der Westmächte vor Hitler,

${ }^{55}$ Vgl. ebenda; Lauren, Diplomats, S. $194 \mathrm{f}$.

${ }^{56}$ Vgl. Remme/Esch, Französische Kulturpropaganda, S. 9 ff.; Young, French Foreign Policy, S. 15; Düwell, Deutschlands auswärtige Kulturpolitik, S. 249 (hier der Hinweis auf die bilateralen Kulturabkommen).

57 Vgl. Les Affaires Etrangères, S. 451; geringfügig abweichende Zahlen bei Lauren, Diplomats, S. 196, der die Jahresbilanzen des Außenministeriums als Quelle anführt.

${ }^{58}$ Dollot, Relations culturelles, S. 38. Insgesamt zur französischen Kulturpolitik der Zwischenkriegszeit: Salon, L'action culturelle, S. $173 \mathrm{ff}$.

$59 \mathrm{Vgl}$. Remme/Esch, Französische Kulturpropaganda, S. $30 \mathrm{ff}$.

${ }^{60}$ Vgl. ebenda, S. 29; Salon, L'action culturelle, S. 205.

61 Vgl. Salon, ebenda 205 ff.; Balous, L'action culturelle, S. $63 \mathrm{f}$; Marès, Puissance, S. $74 \mathrm{ff}$.

${ }^{62}$ Salon verweist auf ein Rundschreiben des Service des CEuvres Françaises à l'Etranger zur ,action intellectuelle" vom 16.1.1933, das ausdrücklich die erfolgreiche Tätigkeit deutscher Wissenschaftler im Ausland vor dem Ersten Weltkrieg als Vorbild bezeichnete, das es zu übertreffen gelte. Auch die Gründung französischer Lehrstühle und Lektorate erfolgte vor allem in Regionen, in denen Deutschland bis 1918 und $z$. T. darüber hinaus besonders aktiv gewesen war: in Nord- und Lateinamerika, Mitteleuropa und dem Donauraum; ebenda, S. 207. 
einen tiefgreifenden Einbruch der französischen Position. Auf dem Balkan stieg das nationalistische Fieber an; zudem sah sich Paris hier in einem verschärften Wettbewerb mit seinen Konkurrenten. Ein ähnlicher Befund gilt für den Nahen Osten. Das in den meisten Fällen nur relative, in Frankreich nichtsdestoweniger schmerzlich empfundene Verblassen des eigenen rayonnement culturel erhielt in Verbindung mit krisenhaften Entwicklungen in Wirtschaft, Finanzen, Handel, Diplomatie und Militärpolitik eine gewisse Brisanz. Dies gilt es zu berücksichtigen, wenn Frankreichs auswärtiger Kulturpolitik der 20er und 30er Jahre ein „stark antideutscher Akzent“ und eine deutlich propagandistische Ausrichtung attestiert wird ${ }^{63}$.

Einen Sonderfall, der gerade in Deutschland ein kritisches Urteil begünstigte, stellten die kulturpolitischen Bemühungen der französischen Militäradministration in den seit Ende 1918 besetzten linksrheinischen Gebieten dar. Hier sollte mit allen erdenklichen Mitteln eine Frankreich gewogene Geisteshaltung in der einheimischen Bevölkerung gefördert werden ${ }^{64}$. Neben der stark militärisch akzentuierten Betonung traditioneller Bindungen zwischen Frankreich und den Rheinlanden, insbesondere seit der Ära Napoleons I., galt vornehmlich die bestehende Sprachbarriere der Besatzungsmacht als Anlaß zur Verordnung obligatorischen Französischunterrichts an den Schulen und zur Einführung von Sprachkursen für Erwachsene. Die Rheinländer sollten befähigt werden, „das französische Gemüt verstehen sowie die Werke und die Kultur der Franzosen würdigen zu können und mit ihnen bessere Beziehungen jeglicher Art in der Zukunft zu pflegen “65. Die Interventionsmaßnahme hatte zwar nur kurzen Bestand, denn nach dem Ende der Waffenstillstandszeit und dem Inkrafttreten des Versailler Friedensvertrages im Januar 1920 entfiel die rechtliche Grundlage für französische Anordnungen im Schulwesen ${ }^{66}$. Doch nutzten die Administratoren um Hochkommissar Tirard die Möglichkeiten des Rheinlandabkommens weidlich aus und setzten nun um so mehr auf die Anziehungskraft „freiwilliger" Sprachkurse ${ }^{67}$. Gleichzeitig waren sie bemüht, antifranzösischer Propaganda vorzubeugen. $\mathrm{Zu}$ diesem Zweck wurden 1919 die an den linksrheinischen Schulen verwendeten Lehrbücher, insbesondere diejenigen für den Geschichts-, Deutsch- und Geographieunterricht, einer genauen Kontrolle unterzogen ${ }^{68}$. Im Gegenzug sollten historische Broschüren, publizistische Erzeugnisse und Filmdokumente die Deutschen von ihrer Kriegsschuld überzeugen. Auch eine „action sur la presse“ wurde in Angriff genommen ${ }^{69}$. Die Kehrseite der Kulturpropaganda ${ }^{70}$ stellten zahlreiche Theater- und Musikdarbietun-

\footnotetext{
${ }_{63}$ So von Düwell, Deutschlands auswärtige Kulturpolitik, S. $44 \mathrm{f}$.

${ }^{64} \mathrm{Vgl}$. Süß, Rheinhessen, S. 41; zum Folgenden auch Brunn, Französische Kulturpolitik; Hüttenberger, Methoden, S. 106 und 120.

65 Der französische Administrator des rheinhessischen Kreises Oppenheim im Februar 1919, zitiert nach Süß, ebenda, S. 45.

${ }^{66} \mathrm{Vgl}$. ebenda, S. 135.

${ }^{67}$ Vgl. ebenda, S. 45 ff., Brunn, ebenda, S. $222 \mathrm{ff}$.

68 Vgl. Süß, ebenda, S. 48.

${ }^{69}$ Vgl. ebenda, S. $50 \mathrm{ff}$; Brunn, ebenda, S. $227 \mathrm{ff}$.

70 Während französische Kulturpolitiker oft ganz unbefangen von „Auslandspropaganda“ sprachen (vgl. Lauren, Diplomats, S. $187 \mathrm{ff}$.), gab es gleichzeitig auch offizielle Stimmen, die betonten, daß Frankreich keine Propaganda betreiben wolle und könne; vgl. Remme/Esch, Französische Kulturpropaganda, S. 1. Tatsächlich kamen bald Bezeichnungen wie „rayonnement de l'esprit français“ oder „rayonnement de la civilisation française“ in Mode; vgl. Epting,
} 
gen französischer Ensembles, ambitionierte Kunstausstellungen und wissenschaftliche wie literarische Vorträge dar, die von der Besatzungsmacht auch über das Jahr 1920 hinaus mit einigem Aufwand organisiert wurden, jedoch insgesamt nicht die erhoffte Resonanz beim einheimischen Publikum fanden ${ }^{71}$. Schließlich zeigten sich die französischen Offiziere und Verwaltungskommissare geneigt, eine Wiederbelebung der um 1800 geschlossenen Mainzer Universität ins Auge zu fassen, um die Ablösung der preußisch-protestantisch geprägten Beamtenschaft und eine stärkere Ausrichtung der linksrheinischen Eliten auf das geistige Leben Frankreichs herbeizuführen. Solche Pläne stießen bei Mainzer Honoratioren, deren Stadt von der Besatzungsmacht zum französischen Bildungszentrum ausgebaut werden sollte, durchaus auf Gegenliebe ${ }^{72}$. Insgesamt aber erwiesen sich die politischen Umstände für die vergleichsweise bescheidenen, doch zumeist als „kulturimperialistisch“ empfundenen Initiativen ${ }^{73}$ der französischen Besatzungsmacht als denkbar ungünstig. $\mathrm{Zu}$ belastet war die Atmosphäre, zu stark die instinktive Ablehnung all dessen, was der „Erbfeind“ den Deutschen aufzuzwingen schien. Zeitgenössische Schmähschriften legen hiervon beredtes Zeugnis $\mathrm{ab}^{74}$. Festzuhalten bleibt, daß die profranzösische Umorientierungspolitik im besetzten Rheinland nach dem Ersten Weltkrieg aus Elementen bestand, die 25 Jahre später - anspruchsvoller projektiert und dimensioniert, vor allem jedoch um zukunftsweisende, völkerverbindende Komponenten bereichert - aufgegriffen werden konnten.

\section{Schmittlein im Dienst des gaullistischen Widerstands}

Unterdessen entwickelte sich der zum Inspecteur de l'enseignement français à l'étranger ernannte Schmittlein auf seinem Posten im Baltikum zum Spezialisten für den Französischunterricht im Ausland, der mehrere Grammatik-, Lese- und Wörterbücher verfaßte. Gleichzeitig ging er seinen wissenschaftlichen Interessen nach, publizierte militärhistorische Studien über Litauen im Zeitalter Napoleons und arbeitete als Linguist über die baltische Frühgeschichte, indem er etymologisch ungeklärte Personen- und Ortsnamen analysierte ${ }^{75}$. Im Sommer 1939, unmittelbar vor dem deutschen Angriff auf Polen, beendete er eine Untersuchung über „Lokis“, die letzte und wenig bekannte Novelle Prosper Mérimées, die erst zehn Jahre später in Buchform erscheinen konnte $^{76}$. Außerdem betätigte er sich seit seiner Ankunft in Kaunas als Korrespondent für die französische Nachrichtenagentur Havas und mehrere Tageszeitungen sei-

\section{Fortsetzung Fußnote von Seite 28}

Französisches Sendungsbewußtsein, S. 201. Dem ist allerdings entgegenzuhalten: „In der Sache handelte es sich [...] um ein Konzept kultureller Expansion, das zum Teil auch Elemente der Kulturpropaganda einschloß"; Düwell, Deutschlands auswärtige Kulturpolitik, S. 44. Vgl. auch Brunn, Französische Kulturpolitik, S. 223 und $238 \mathrm{ff}$.

${ }^{71}$ Vgl. Süß, Rheinhessen, S. 50 und $139 \mathrm{ff}$; Brunn, ebenda, S. $231 \mathrm{ff}$.

${ }^{2}$ Vgl. Süß, ebenda, S. 138; Brunn, ebenda, S. 226.

${ }^{3}$ So in Anlehnung an Düwells Typologie das Urteil bei Brunn, ebenda, S. 239.

74 Vgl. Hartmann, Französische Kulturarbeit, S. 5; Kaden/Springer, Politischer Charakter, S. 10 und 62.

75 Vgl. die Bibliographie bei Manns, Höchst persönliche Erinnerungen, S. $258 \mathrm{ff}$.

${ }^{76}$ Schmittlein, Lokis. 
nes Landes ${ }^{77}$. In dieser Eigenschaft beobachtete er die prekäre politische Lage Nordosteuropas im Vorfeld des Hitler-Stalin-Pakts, die rivalisierenden Ansprüche und $\mathrm{Be}$ gehrlichkeiten des Deutschen Reiches, der Sowjetunion und Polens.

Bei Kriegsbeginn wurde der Reserveoffizier Schmittlein zum stellvertretenden Militärattaché in Riga ernannt. Als er bei einer Geheimdienstaktion Ende 1939 in die Mühlen des NKWD, der Gestapo sowie der lettischen politischen Polizei geriet und tagelang verhört wurde, mußte er nach Skandinavien fliehen ${ }^{78}$. Stockholm, Helsinki und Narvik waren die wichtigsten Stationen im Frühjahr 1940. Nachdem er auf norwegischer Seite - wie der einem britisch-französischen Expeditionskorps angehörende Commandant Pierre Koenig - am Polarkreis gegen deutsche Gebirgsjäger gekämpft hatte, erfuhr er in der schwedischen Hauptstadt von Frankreichs Kapitulation und de Gaulles Widerstandsappell aus London. Die Anordnung des Pétain-Regimes, nach Frankreich zurückzukehren, wollte er nicht befolgen; sein Entschluß, nach England zu fliegen, wurde durch die deutsche Luftwaffe vereitelt. So schlug er sich auf abenteuerlichen Wegen durch Rußland und die Türkei nach Griechenland durch, von wo ihn ein britischer Kreuzer nach Ägypten brachte. Er kämpfte im Dezember 1940 mit den ersten Einheiten der Forces Franf̧aises Libres in Libyen, bevor er in politischer Mission nach Nahost entsandt wurde. In den französischen Mandatsgebieten Syrien und Libanon, wo es an der Seite Großbritanniens, aber auch in ständiger, konfliktreicher Abgrenzung zu den Briten, die Position Vichys und der Achsenmächte zu bekämpfen galt, betrieb er zunächst mit Kameraden den geheimen Rundfunksender Levant France Libre, wurde nach der Kapitulation der Vichytruppen im Juli 1941 in den Stab von de Gaulles Hochkommissar General Catroux berufen, um dessen Nachrichtendienst zu reorganisieren, und erhielt schließlich den heiklen Auftrag, die Entwaffnung des Libanon durchzuführen. In dieser Zeit schloß Schmittlein Freundschaft mit jüdischen Untergrundkämpfern, die später zur politischen Führungsgruppe des Staates Israel gehörten. Aber auch im Umgang mit den arabischen Bevölkerungsteilen bewies er genügend Geschick, um - trotz englischer Gegenaktionen - seine Mission erfolgreich zu beenden.

Im Januar 1942 erreichte ihn die Weisung de Gaulles aus London, sich als stellvertretender Leiter der neu eingerichteten Delegation des Freien Frankreich in die Sowjetunion $^{79}$ zu begeben. In Moskau und Kuibyschew an der Wolga, wohin seit Oktober 1941 mehrere sowjetische Regierungsstellen und das diplomatische Corps evaku-

77 Vgl. [Anonym,] Raymond Schmittlein, S. 15.

${ }^{78}$ Vgl. Cathala, Sans fleur, S. 48 und 258, wo allerdings nur NKWD-Agenten als Akteure auftreten. Während in [Anonym,] Raymond Schmittlein, S. 7, und Manns, Höchst persönliche Erinnerungen, S. $35 \mathrm{f}$., die Kooperation von Gestapo und NKWD bei der Verhaftung Schmittleins ausdrücklich erwähnt wird, ist bei Delcroix, Un destin, S. 5, nur von deutschen Agenten die Rede. Möglicherweise geht dies auf politische Rücksichtnahmen Schmittleins selbst zurück, der seit 1957 Vorsitzender der Association France-URSS war und bei seinen gaullistischen Parteifreunden nachhaltig für freundschaftliche Beziehungen zur Sowjetunion warb. Cathala bezeichnet ihn gar als ,prosowjetischen Fundamentalisten“, der sich 1968 die Argumente des Kreml zur Rechtfertigung der militärischen Intervention in der CSSR zu eigen gemacht habe; ebenda, S. 328.

79 Zur Einrichtung dieser Delegation Dejeans Aufzeichnung „Position internationale de la France Combattante" vom 6.3.1943; in: MAE, Y/41, fol. 2 ff. 
iert wurden, hatten die Emissäre des Generals verschiedene Aufgaben zu erfüllen ${ }^{80}$. Zunächst mußten zuverlässige Informationen über Rußlands militärisches und industrielles Potential, seine kurzfristig mobilisierbaren Widerstandskräfte gegenüber dem deutschen Angreifer nach London übermittelt werden. In dieser Hinsicht erhielt de Gaulle weitaus optimistischere Prognosen als Churchill und Roosevelt ${ }^{81}$. Darüber hinaus sollte französische Kampfbereitschaft an der Seite der Sowjetunion demonstriert werden, auch wenn sich dies weitgehend auf symbolische Akte beschränkte. Im August 1943 empfing Außenminister Molotow den stellvertretenden Delegationsleiter Schmittlein, der dem Comité Français de Libération Nationale in Algier die Anerkennung als Repräsentant der französischen Staatsinteressen durch die sowjetische Regierung übermitteln sollte ${ }^{82}$. $\mathrm{Zu}$ einem Teilerfolg führte schließlich der wiederholt den Kremlherren vorgetragene Wunsch, die in die deutsche Wehrmacht gezwungenen, von der Roten Armee kriegsgefangenen Elsässer und Lothringer freizulassen und den freifranzösischen Truppen zuzuführen. Nach langem Tauziehen konnte im Sommer 1944 ein kleines Kontingent dieser Malgré-nous die UdSSR verlassen ${ }^{83}$.

Schmittlein, der den Sohn des späteren Staats- und Parteichefs Chruschtschow und den Schriftsteller Ilja Ehrenburg zu seinen Freunden zählte ${ }^{84}$, fühlte sich in der Sowjetunion offenkundig wohl. Hier, so ahnte er, würde sich der Krieg entscheiden. Die Sowjetrussen waren in seinen Augen die einzig zuverlässigen Partner, auf die man 1938 hätte hören müssen, um der „Schmach von München“ zu entgehen ${ }^{85}$. So dachten wohl die meisten in der Delegation, die Schmittlein als „hundertprozentig prosowjetisch" charakterisiert haben soll. Mit Dankbarkeit und Bewunderung nahmen die Exilfranzosen russische Kampfmoral und Opferbereitschaft zur Kenntnis; Berührungsängste aus ideologischen Gründen schienen sie nicht zu kennen ${ }^{86}$. Wenn Schmittlein im Kollegenkreis über den „Verrat der Eliten“ und die „200 Familien“ der französischen Oberschicht räsonnierte, griff er häufig benutzte Topoi aus den Rundfunkansprachen de Gaulles auf ${ }^{87}$. In einem weiteren Sinne verstanden, trifft die Aussage eines Beteiligten vermutlich zu, daß allen Mitgliedern der Delegation „das Herz politisch links“ geschlagen habe ${ }^{\mathbf{8 8}}$. Doch eine rein diplomatische Mission behagte Schmittlein auf Dauer nicht; er wünschte sich ein militärisches Kommando bei einer Panzer- oder Fallschirmjägereinheit ${ }^{89}$. Es kam hinzu, daß sein selbstbewußtes, gelegentlich aufbrausendes und schroffes Auftreten nicht nur das ohnehin gespannte

80 Hierzu Cathala, Sans fleur, S. $253 \mathrm{ff}$.

81 Vgl. ebenda, S. 263 ff., 271 f. und 289; Giraud, De Gaulle, t. I, S. 83 ff.

82 Vgl. Cathala, Sans fleur, S. 322.

${ }^{83}$ [Anonym, Raymond Schmittlein, S. 10, und Manns, Höchst persönliche Erinnerungen, S. $43 \mathrm{f}$, berichten, daß bereits im Herbst 1943 eine Truppe von 2000 Elsāssern und Lothringern über Iran den FFL zugeführt worden sei. Cathala erinnert sich hingegen, daß erst im Juli 19441700 haftentlassene „Malgré-nous“ dem Befreiungskomitee zur Verfügung gestellt wurden; Sans fleur, S. 303 und 312. Diese Version wird als annāhernd korrekt bestätigt durch Schaeffer, L'Alsace, S. 21.

${ }^{84} \mathrm{Zu}$ Chruschtschow vgl. Cathala, Sans fleur, S. 264, 272 und 302; zu Ehrenburg: Delcroix, Un destin, S. 22.

85 Cathala, Sans fleur, S. 255.

${ }^{86}$ Vgl. ebenda, S. 263 und 273 f.; Giraud, De Gaulle, t. I, S. 466 ff.

87 Cathala, Sans fleur, S. 255. Vgl. auch Touchard, Le gaullisme, S. $51 \mathrm{ff}$.

88 Cathala, ebenda, S. 295.

89 Vgl. ebenda, S. 258 und 302. 
Verhältnis zu den amerikanischen Vertretern in der Sowjetunion zusätzlich belastete, sondern auch zum Zerwürfnis mit seinem Vorgesetzten führte ${ }^{90}$.

Als Schmittlein im August 1943 aus Moskau abberufen und nach Algier versetzt wurde, erhielt er allerdings erneut einen zivilen Aufgabenbereich im Stab de Gaulles zugewiesen. Hier traf er mit führenden Männern der innerfranzösischen und gaullistischen Résistance zusammen, die nun die provisorische Exilregierung Frankreichs bildeten und später zu den einflußreichsten Politikern, Diplomaten und Publizisten der Vierten Republik gehörten. Für kurze Zeit arbeitete er mit dem Innenkommissar und Gründer der Widerstandsgruppe Libération-Sud d'Astier de la Vigerie zusammen" Im Frühjahr 1944 saß er als Generalsekretär im Exekutivausschuß der algerischen Filiale von Combat neben den Gründungsmitgliedern Henri Frenay, Kommissar für Kriegsgefangene, Deportierte und Flüchtlinge ${ }^{92}$, und René Capitant, Juraprofessor, Gaullist der ersten Stunde und Erziehungskommissar im Nationalen Befreiungskomitee. Auch den Rechtsanwalt Giron und dessen Frau Irène, seine spätere Stellvertreterin in der Baden-Badener Erziehungsdirektion, lernte er hier kennen ${ }^{93}$.

Die in der Südzone Frankreichs wohl stärkste und bestorganisierte, ein Spektrum vor allem christdemokratisch-katholischer und gemäßigt linker Mitglieder umfassende Widerstandsgruppe Combat entwickelte sich im Laufe der Zeit zur gaullistischen Speerspitze unter den verschiedenen Bewegungen. Ihre aktive, einflußreiche Außenstelle in Algerien leistete seit 1942 dem in Nordafrika umstrittenen de Gaulle propagandistische Schützenhilfe gegen seine Kontrahenten Darlan und Giraud und erleichterte ihm so die Durchsetzung seines politischen Führungsanspruches. Als Sammelbecken der republikanischen und demokratischen Elemente sollte Combat d'Alger nach der Bildung des Nationalen Befreiungskomitees im Mai 1943 bei der Vereinigung aller überseeischen Widerstandsgruppen, dann aber auch bei der Eindämmung kommunistischer Machtansprüche innerhalb der Résistance eine wichtige Rolle spielen ${ }^{94}$. Schließlich erschienen seit Ende 1943 zahlreiche programmatische Artikel und Broschüren, die die Vorstellungen von Combat zur Lösung der drängendsten $\mathrm{Zu}-$ kunftsaufgaben deutlich machten und zumeist in eindringlicher Weise einen „revolu-

${ }^{90}$ Zum gespannten Verhältnis zwischen Amerikanern und Gaullisten in der Sowjetunion vgl. ebenda, S. 295 ff.; Krautkrämer, Frankreichs Kriegswende 1942, S. 275. Allgemein zum Verhältnis USA - France Libre - Vichy: Hurstfield, America. Zum Zerwürfnis Schmittleins mit Missionschef Garreau: Cathala, Sans fleur, S. 305 und 322. Daß Schmittlein aufbrausend reagieren konnte, wird deutlich ebenda, S. 319 f.; bestätigt hat diese Eigenschaft auch Robert Marquant in einem Gespräch am 7.4.1989.

${ }^{91}$ Vgl. Delcroix, Un destin, S. 10; zu Libération-Sud und d'Astier Michel, Les courants, passim.

92 Der Berufsoffizier Frenay muß ein Jahrgangskamerad Schmittleins an der Militärakademie Saint-Cyr gewesen sein, denn nach Granet/Michel, Combat, S. 28, trat Frenay 1924 in SaintCyr ein.

${ }^{93}$ AN, $\mathrm{F}^{17}$ 13335, diverse Korrespondenz; zur Rolle Irène Girons in Algier, bei Combat und im Kabinett des Erziehungskommissars Capitant die biographischen Angaben in: Heinemann (Hrsg.), Hochschuloffiziere, S. $195 \mathrm{ff}$.

94 Vgl. Granet/Michel, Combat, S. 28 ff., $220 \mathrm{ff}$., 285, $307 \mathrm{ff}$; Michel, Les courants, S. $266 \mathrm{ff}$., $614 \mathrm{ff}$; Lacouture, De Gaulle, t. I, S. $805 \mathrm{ff}$. Den Kampf gegen das Erstarken kommunistischer Positionen innerhalb von France Combattante betont besonders [Anonym, Raymond Schmittlein, S. 10f. In AN, $F^{17} 13335$ finden sich zwar Hinweise auf eine Auseinandersetzung Schmittleins als Generalsekretār von Combat d'Alger mit France Combattante de Tunisie, doch werden ideologische Hintergründe dabei nicht sichtbar. 
tionären Humanismus“ postulierten oder für die Verwirklichung eines freiheitlichen Sozialismus plädierten ${ }^{95}$.

$\mathrm{Zu}$ den Problemen, die es im Frankreich der Nachkriegszeit anzupacken galt, gehörte nach Meinung der Exil- und Résistancegruppen eine tiefgreifende Reform des gesamten Erziehungswesens. Hierüber wurden 1943/44 nicht nur programmatische Reflexionen angestellt ${ }^{96}$, sondern bereits konkrete Maßnahmen beraten. Bei einer solchen Gelegenheit konnte sich Schmittlein unter den Augen des designierten Pariser Erziehungsministers als engagierter Pädagoge profilieren. Capitant rief im Januar 1944 eine Kommission für die Reform des Unterrichtswesens ins Leben, die für die Zeit nach der Befreiung Frankreichs eine Erneuerung der alten Erziehungsinstitutionen nach den republikanischen Fundamentalprinzipien Liberté-Egalité-Fraternité erarbeiten sollte. Mit dieser programmatischen Vorgabe trat die Kommission in Algier am 8. März 1944 erstmals zusammen; sie tagte im folgenden allwöchentlich unter dem Vorsitz Capitants oder ihres Vizepräsidenten, des Sorbonne-Professors Marcel Durry. Als in der Eröffnungssitzung sechs Unterausschüsse gebildet wurden, meldete sich das Kommissionsmitglied Schmittlein ${ }^{97}$ zu den beiden Arbeitsgruppen, die sich mit den weiterführenden Schulen und Fragen der Lehrerausbildung befaßten. Seine Anregung, einen Ausschuß für das französische Unterrichtswesen im Ausland einzurichten, fand keine Resonanz ${ }^{98}$. Nach fünfmonatigen, oftmals kontroversen Beratungen legte Durry im September 1944 einen Abschlußbericht vor, der als Diskussionsgrundlage für Öffentlichkeit und Parlament nach der Befreiung Frankreichs dienen sollte ${ }^{99}$. Da hierin explizit an frühere Schulreformpläne angeknüpft wurde, erscheint vor einer Analyse des Algier-Projekts und Schmittleins Rolle dabei ein kurzer historischer Rückblick angebracht.

\section{Schulreformbestrebungen in Frankreich seit 1918}

Unmittelbar nach dem Ersten Weltkrieg wandte sich eine Gruppe junger Intellektueller - unter ihnen der gerade 30jährige Edmond Vermeil -, mit der Forderung nach

${ }_{95}$ Vgl. die zeitgenössischen Zeugnisse: Frenay, Combat; Hauriou, Vers une doctrine; Gérard, Que faire; ferner die Analyse von Michel, Les courants, S. $387 \mathrm{ff}$.; Textauszüge bei Lipgens, Europa-Föderationsplāne, S. 216 ff., 227 ff., 236 ff.; Ziebura, Deutsch-französische Beziehungen, S. $29 \mathrm{f}$.

96 Vgl. z. B. Hauriou, ebenda, S. $56 \mathrm{ff}$.

97 Erstaunlicherweise hat Schmittlein seine Mitarbeit in diesem Gremium nie publik gemacht. Auch Robert Marquant, sechs Jahre lang Schmittleins "rechte Hand“ in Baden-Baden, war diese Tatsache nicht geläufig, wie er im Gespräch am 7.4.1989 bekannte. Vgl. Marquants Hinweis auf die vom Verf. erstmals ausgewerteten Dokumente in: Heinemann (Hrsg.), Hochschuloffiziere, S. 23, wo allerdings aufgrund eines Druckfehlers eine falsche Archivsignatur angegeben ist.

${ }^{8}$ AN, $\mathrm{F}^{17}$ 13335, Sitzungsprotokolle der Commission de la Réforme de l'Enseignement. Die Kommission wurde durch zwei Dekrete am 21.1.1944 ins Leben gerufen und tagte vom 8.3. bis 2.8.1944 regelmäßig jeden Mittwoch. Schmittlein nahm bis Mitte Juli an den Zusammenkünften teil.

99 In der letzten protokollierten Sitzung wurde der Termin der nächsten Zusammenkunft nicht festgelegt. Man beschloß lediglich, daß diese "so bald wie möglich“ stattfinden solle, um den Abschlußbericht (rapport général) des Vizepräsidenten Durry zu hören (Sitzungsprotokoll vom 2.8.1944). Dieser Bericht liegt in AN, $F^{17} 13335$ nicht vor, wird daher im folgenden zitiert nach Schneider, Neue Erziehung, S. $70 \mathrm{ff}$. Vgl. auch Miles, Recent Reforms, S. 45 ff.; Honig, Schulreformen, S. $150 \mathrm{ff}$; Knaup, Beobachtungs- und Orientierungsstufe, S. $26 \mathrm{ff}$. 
einer Reorganisation des gesamten Bildungswesens an die französische Öffentlichkeit $^{100}$. Die Compagnons de l'Université Nouvelle erstrebten den Wiederaufbau Frankreichs mit Hilfe eines enseignement fraternel in der école unique, einer für alle sechs- bis vierzehnjährigen Kinder gemeinsamen, nicht mehr schichten- oder klassenspezifischen Elementarschule, die unter der Losung „soziale Gerechtigkeit“ gesellschaftliche Aufstiegschancen für alle Begabten ohne Berücksichtigung ihrer Herkunft ermöglichen und die strikte Trennung zwischen Primar- und Sekundarschulbereich überwinden sollte. Die Primarschule bereitete bis dahin vor allem Kinder der unteren Schichten auf eine Berufsausbildung vor, wurde jedoch von vielen Zwölfjährigen bereits verlassen. Die Sekundarstufe führte vornehmlich den Nachwuchs begüterter Kreise zum Abitur und öffnete ihm damit den Weg zum Hochschulstudium. Die programmatische Schrift der Compagnons forderte im Zuge ihrer radikalen Infragestellung des gesamten öffentlichen Erziehungssystems die Beobachtung, Begabungsfindung und Orientierung der Elf- bis Vierzehnjährigen, um eine Auswahl für die weiterführenden Schulen treffen zu können. Die Betonung "sozialer Gerechtigkeit" und besserer Nutzung des nationalen geistigen Potentials verband sich in diesem Entwurf mit dem Fortwirken traditioneller Vorstellungen von Kultur, Elitenbildung und Begabtenselektion.

Auch wenn die Reformideen der Compagnons zunächst an mannigfachen Widerständen scheiterten, konnte sich die Einheitsschulbewegung immerhin einen späten Teilerfolg anrechnen, als zwischen 1932 und 1936 die schrittweise Einführung der Schulgeldfreiheit an Gymnasien und die Schulpflichtverlängerung bis zum vierzehnten Lebensjahr beschlossen wurde ${ }^{101}$. Im Juni 1936 fand ein bedeutender Pädagogenkongreß in Le Havre statt, bei dem die fortbestehende Diskrepanz zwischen Ideal und Wirklichkeit des französischen Bildungssystems scharf kritisiert wurde ${ }^{102}$. Zur selben Zeit bildete in Paris Léon Blum die erste Volksfrontregierung, in der ein junger Mann namens Jean Zay Erziehungsminister wurde. Ein Dreivierteljahr später legte dieser dem Parlament einen Gesetzentwurf zur Reform des Unterrichtswesens vor, in den die Vorstellungen der Compagnons ebenso eingeflossen waren wie die Ideen eines rein sozialistischen Alternativprojekts ${ }^{103}$. Zay, der aus dem Bildungsbereich ein „Werk der Gerechtigkeit und ein Instrument des sozialen Fortschritts“ machen wollte ${ }^{104}$, setzte den Schwerpunkt auf eine stärkere Vereinheitlichung und größere Durchlāssigkeit der Sekundarstufe. Die Sexta sollte Orientierungsklasse werden, nach deren Resultaten die Schüler anschließend auf drei Sektionen - eine klassische, eine moderne und eine technische - aufzuteilen waren. Neben den Prinzipien der Begabungsförderung und der Selektion stand das der Orientierung im Mittelpunkt, da Zay die endgültige Festlegung elfjāhriger Kinder auf einen bestimmten Bildungsweg für verfrüht und pädago-

100 Das Folgende nach Miles, ebenda, S. 25 ff.; Honig, ebenda, S. 69 f.; Knaup, ebenda, S. $18 \mathrm{ff}$.

101 Vgl. Schneider, ebenda, S. 43 ff.; Knaup, ebenda, S. 22. Zu den in Deutschland diskutierten reformpädagogischen Konzeptionen, die in vielem jenen der französischen Einheitsschulbewegung ähnelten, vgl. Flitner/Kudritzki (Hrsg.), Deutsche Reformpādagogik; Neuner, Bund; Wittwer, Sozialdemokratische Schulpolitik.

102 Vgl. Schneider, ebenda, S. $48 \mathrm{ff}$.

${ }^{103}$ Vgl. zum Folgenden ebenda, S. 55 f.; Knaup, ebenda, S. 22 ff.; der Hinweis auf den Einfluß des Sorbonne-Professors und Sozialisten Zoretti bei Honig, ebenda, S. 70.

${ }^{104}$ Zitiert nach Knaup, ebenda, S. 22. 
gisch nicht vertretbar hielt. Besonderen Nachdruck legte der Erziehungsminister, in Übereinstimmung mit dem Kongreß von Le Havre, auf die Verwendung "aktiver" Unterrichtsmethoden, die von Schulreformern seit Anfang des Jahrhunderts gefordert wurden und das Ziel verfolgten, die Eigenständigkeit der Schüler zu wecken. Zays Reformvorstellungen kamen aufgrund einflußreicher Widerstände über die versuchsweise Einführung von Orientierungsklassen seit Winter 1937/38 nicht hinaus. Auch die gesamtpolitische Entwicklung trug das Ihre bei. Der abgesetzte Erziehungsminister wurde nach Frankreichs Kapitulation verhaftet und schließlich kurz vor der Befreiung 1944 von Landsleuten ermordet ${ }^{105}$. Immerhin hatten die seit langem virulenten Vereinheitlichungsbestrebungen im Schulwesen unter der Volksfront ihren regierungsamtlichen Ausdruck erhalten, an den sich bei der Nachkriegsplanung in Résistancekreisen um so mehr anknüpfen ließ, als das Vichy-Regime Zays Projekt nicht zuletzt aus ideologischen Gründen im Keim erstickte. Eine Ausgabe der Untergrundpublikation „Les Cahiers. Etudes pour une révolution française“ vom September 1942 widmete sich ausschließlich Fragen der Erziehung und des Unterrichts ${ }^{106}$ und stellte ein wichtiges Bindeglied geistiger Kontinuität zwischen dem Volksfrontentwurf von 1937 und jenen zehn Reformprojekten dar, die zwischen 1944 und 1956 von verschiedenen Seiten Parlament und Öffentlichkeit der Vierten Republik vorgelegt wur$\operatorname{den}^{107}$.

Auch in der Umgebung de Gaulles im Londoner Exil machte man sich zur selben Zeit Gedanken über die Aufgaben der Nachkriegszeit. Bereits im November 1940 plädierte ein Angehöriger von France Libre für die Einsetzung eines Expertengremiums, das Vorstellungen zu den wichtigsten Fragen in Politik, Wirtschaft und Gesellschaft Frankreichs, des Empire und Europas entwickeln sollte ${ }^{108}$. Erst Anfang Dezember 1941 indessen beauftragte de Gaulle vier Kommissionen, sich mit den Nachkriegsproblemen zu befassen ${ }^{109}$. Das ehrgeizig anmutende Planungsunternehmen konnte hochgestellte Erwartungen allerdings nicht erfüllen ${ }^{110}$. Nur auf den ersten Blick beeindruckt die Bilanz einer Section intellectuelle et de l'enseignement, die von Juli 1942 bis Juli 1943 unter Leitung des Professors J. Cathala regelmäßig tagte ${ }^{111}$ und sich mühsam auf einige Grundprinzipien für eine Reform des französischen Unterrichtswesens verständigte $^{112}$. Seit längerem öffentlich diskutierte Probleme kamen in dem mehrmonatigen Meinungsaustausch zur Sprache: die Rolle von Staat und Kirche im Erziehungsbereich, eine Koordination von Primar- und Sekundarschulwesen, die Ausdehnung des Schulpflichtalters, Probleme der Lehrplanüberfrachtung, die Wiedereinführung von Orientierungsklassen und der ebenfalls unter Pétain geschlossenen Ecoles normales zur Lehrerausbildung, die Gestaltung der gymnasialen Züge, Unterrichtsmethoden,

${ }_{103}$ Vgl. Schneider, ebenda, S. $61 \mathrm{ff}$. und 156; Knaup, ebenda, S. $23 \mathrm{ff}$.

${ }_{106}$ Ausführlich wiedergegeben bei Schneider, ebenda, S. $64 \mathrm{ff}$.

107 Uberblick bei Honig, ebenda, S. $130 \mathrm{ff}$.

${ }^{108} \mathrm{MAE}$, Guerre 1939-45, Londres, CNF/172, fol. 1 f., Aufzeichnung Bernards von [Anf.] November 1940 .

109 Ebenda, fol. 4, 9, 67, 89.

110 Ebenda, fol. 309 ff., 321.

11 Ebenda, fol. 81, 160; vol. 186, fol. $82 \mathrm{ff}$.

112 Ebenda, vol. 172, fol. 160 ff.; vol. 186, fol. 2. 
Fragen der beruflichen und der Erwachsenenbildung ${ }^{13}$. Doch zu einem in sich geschlossenen, über Grundsatzerklärungen hinausgehenden Gesamtentwurf gelangte Cathalas Studiengruppe nicht. Mit der Installierung der provisorischen Exilregierung de Gaulles in Nordafrika scheint sie sang- und klanglos auseinandergegangen zu sein; eine Koordination zwischen Schulpolitikern in Algier und London ließ sich aufgrund der kriegsbedingt schwierigen Verbindungen kaum aufrechterhalten ${ }^{114}$.

\section{Die Schulreformkommission in Algier (1944)}

Zwar waren die Londoner Diskussionen dem Vizepräsidenten der Algier-Kommission bekannt ${ }^{115}$, doch nannte Durrys Abschlußbericht vom September 1944 andere Bezugspunkte. Ausdrücklich war davon die Rede, daß man angesichts des ,allgemeinen Wunsches nach einer wahren Revolution und nach einem verjüngten Vaterland“ an die Einheitsschulbewegung der Compagnons und die Reformen Zays anknüpfen und energisch radikale Maßnahmen ergreifen müsse. Es gelte jedoch, nicht nur aus den eigenen bitteren Erfahrungen Lehren zu ziehen, sondern sich auch von Entwicklungen im Ausland inspirieren zu lassen ${ }^{116}$. Tatsächlich führten zur selben Zeit, im August 1944, die englischen Schulreformbestrebungen zur Annahme des seit Monaten verhandelten Education Act, der jedoch stärker traditionsgebundene Schwerpunkte setzte ${ }^{117}$. Im übrigen griff die Kommission auch Vorschläge aus dem besetzten Frankreich und von Exilgruppen in Nordafrika auf ${ }^{118}$.

Welches Programm wurde nun in Algier entworfen, welche Rolle und welche Positionen nahm dabei das Ausschußmitglied Schmittlein ein ${ }^{119}$ ? Daß er in wesentlichen

113 Die Section intellectuelle et de l'enseignement setzte sich auch mit einem konkurrierenden Reformentwurf auseinander, der in Frankreich erarbeitet worden war und Anfang 1943 zur Stellungnahme im Londoner Hauptquartier von France Libre eintraf. Dieses umfangreiche Memorandum („Bases d'un Ministère de la Vie Culturelle") wurde in einem Dutzend Einzelstudien der Section unter verschiedenen Gesichtspunkten kritisch beleuchtet (ebenda, vol. 172, fol. $261 \mathrm{ff}$; vol. 186, fol. $30 \mathrm{ff}$.). Das Memorandum selbst wurde nicht ermittelt, so daß über seine Autoren nichts gesagt werden kann.

114 MAE, Guerre 1939-45, Alger, CFLN-GPRF/631, fol. 1, Telegramm Massiglis an de Gaulle vom 7.7.1943; fol. 186, Telegramm Capitants an J.-C. Paris vom 30.8.1944.

115 Ende 1943 wurde Cathala offenbar nach Algier entsandt, um die Erträge seiner Section in die weitere Planungsarbeit einzubringen (ebenda, fol. 41). Eine personelle Kontinuität zwischen der Londoner Studiengruppe und der Reformkommission in Algier bestand jedoch nicht. Cathala wurde zwar in den Sitzungsprotokollen als Mitglied des Capitant-Durry-Ausschusses angeführt, nahm aber an keiner Zusammenkunft teil.

116 Zitiert nach Schneider, Neue Erziehung, S. 70; vgl. auch Knaup, Beobachtungs- und Orientierungsstufe, S. 26. Nach Miles, Recent Reforms, S. 49, wurden in der Algier-Kommission zwei Berichte über die englische Schulreform von 1944 sowie über die „progressive education" an New Yorker Grundschulen herangezogen, jedoch nur in geringem Maße berücksichtigt.

117 Hierzu Honig, Schulreformen, S. 105 ff. France Libre hatte direkten Kontakt zum britischen Erziehungsministerium, da seit Oktober 1942 eine Konferenz der alliierten Erziehungsminister in London über „educational questions affecting Allied countries of Europe and the United Kingdom both during the war period and in the post-war period" beriet; vgl. Allied Plan for Education, S. 1.

118 Dies wurde im Abschlußbericht der Algier-Kommission ausdrücklich vermerkt.

119 Der Abschlußbbericht wird nach der in Anm. 99 angeführten Literatur wiedergegeben, die Positionen Schmittleins nach den Sitzungsprotokollen und einem undatierten Memorandum 
Fragen den Gang der Beratungen mitbestimmte und dem Abschlußbericht seinen Stempel aufzudrücken verstand, zeigte sich vor allem im Bereich der höheren Schulen. Die drei Grundprinzipien der Kommission - den durch die Kriegsereignisse bewirkten Bruch der Traditionen für radikale Neuerungen zu nutzen; soziale Gerechtigkeit durch Chancengleichheit aller Schüler anzustreben; einer Orientierungsphase für alle Jugendlichen Vorrang gegenüber Selektionsgesichtspunkten einzuräumen, gleichzeitig aber auch die Rekrutierung begabter Führungskräfte wichtig zu nehmen - entsprachen im wesentlichen den von Schmittlein vertretenen Auffassungen. Daß diese sich in die für große Teile der französischen Lehrerschaft repräsentative Tradition linksrepublikanisch-aufklärerischer Prägung einreihten, bewies Schmittlein mit einem Memorandum für seine Kommissionskollegen. Die bisherige Zweiteilung des französischen Schulsystems in ein geringer geachtetes Primar- und Berufsschulwesen und ein elitebildendes Sekundarschulwesen entspreche der gesellschaftlichen Spaltung in die "große Masse des Volkes“ und eine „bürgerliche Welt", hieß es darin. Zwischen beiden Systemen bestehe in der Regel keine Durchlāssigkeit. Diesen Status quo aufrechtzuerhalten bedeute, die von der Schule ausgehende Ungleichheit zu konservieren. Künftig müsse es jedem französischen Kind möglich sein, seine Fähigkeiten frei zu entfalten und den ihm angemessenen Bildungsweg einzuschlagen ${ }^{120}$. Schmittleins Handschrift zeigte sich auch bei der grundsätzlichen Frage des Laizismus und des staatlichen Unterrichtsmonopols. Vermutlich auf sein Insistieren hin ${ }^{121}$ wurde die im Abschlußbericht postulierte Laisierung der Staatsschule als Neutralităt in Fragen der Philosophie und Weltanschauung, der Religion und Politik näher definiert ${ }^{122}$, das künftige Schicksal der Privatschulen aber zum politischen Problem erklärt und seine Behandlung daher aufgeschoben ${ }^{123}$.

Als der Unterausschuß für den weiterführenden Unterricht dem Plenum seinen Bericht vorlegte, plädierte insbesondere Schmittlein für eine Vereinheitlichung dieses Sektors. Er legte Grundsätze dar, die für seine später in der französischen Besatzungszone Deutschlands vertretene Schulpolitik aufschlußreich sind. Die acht Schuljahre umfassende Sekundarstufe sollte demnach in zwei gleich lange Zyklen unterteilt werden. Im ersten gelte es, den Elf- bis Vierzehnjährigen vor allem Kenntnisse in einer modernen Fremdsprache (Deutsch, Englisch oder Russisch) zu vermitteln, die alten Sprachen jedoch auszuklammern und einen Auslese- und Spezialisierungsprozeß zu ermöglichen, der nicht zu früh erfolgen dürfe. Nach einer für alle Schüler gleichen Orientierungsphase von zwei Jahren sollte die Aufspaltung in eine literarische und

\section{Fortsetzung Fußnote von Seite 36}

„Enseignement du $2^{e}$ degré - Projet Schmittlein“, in: AN, F ${ }^{17}$ 13335. Die von Jürgen Fischer angesprochene „historisch wichtige Kontroverse", ob Schmittlein und seine Mitstreiter in Algier auch schon über Reformen im deutschen Schulwesen beraten haben (in: Heinemann (Hrsg.), Hochschuloffiziere, S. 23, Anm. 60), läßt sich aufgrund der ermittelten Dokumente nicht beenden.

120 „Projet Schmittlein“. Die darin geäußerte Ansicht, daß gegenwärtig die „Faulenzer“ an den höheren Schulen verblieben, während die überwāltigende Mehrheit der guten Volksschüler nicht aus dem Primarbereich aufsteige, findet sich sinngemäß auch im Abschlußbericht Durrys; vgl. Schneider, Neue Erziehung, S. 71.

121 Sitzungsprotokoll der Reformkommission vom 15.3.1944.

122 Vgl. Honig, Schulreformen, S. 150.

123 Vgl. Schneider, Neue Erziehung, S. 71. 
eine mathematisch-naturkundliche Abteilung erfolgen. Am Ende des ersten Zyklus war ein Abschlußzeugnis vorgesehen. Der zweite Teil würde den Schülern vorbehalten sein, die sich für höhere Bildung (,un enseignement de culture") aufnahmefähig zeigten, wāhrend die übrigen auf stärker technisch-praktisch ausgerichtete Lehranstalten hinzulenken seien. Im Aufbauzyklus müßte entweder die erste Fremdsprache (literarische Sektion) oder Mathematik (naturkundliche Sektion) vertieft und in jedem Fall eine zweite moderne Sprache oder Latein erlernt werden. Während Griechisch, Physik und Chemie gänzlich aus den Schulen verbannt werden und den Universitäten vorbehalten bleiben sollten, wünschte Schmittlein den Philosophieunterricht auf die beiden letzten Klassen ausgedehnt ${ }^{124}$. In der Diskussion zeigte sich, daß bei konservativeren Kommissionsmitgliedern das Konzept einer allgemeinbildenden Orientierungsstufe für alle Schüler nicht nur auf praktische Einwände, sondern auch auf Skepsis grundsätzlicher Art stieß: Kann und soll denn allen Kindern derselbe Unterricht erteilt werden, lautete die kritische Frage eines Kollegen. Ihm hielt Schmittlein nachdrücklich das Gleichheitsprinzip entgegen und bestritt - ganz im Sinne Zays -, daß schon bei Elfjährigen eine Auslese getroffen und eine Spezialisierung gewählt werden könne $^{125}$. Mit dieser Auffassung fand er letztlich eine Mehrheit. In Durrys Abschlußbericht wurde eine zweijährige Orientierungsstufe (Sexta und Quinta) postuliert, die als quasi eigenständige Phase zwischen Primar- und Sekundarbereich konzipiert war und keine Differenzierungen aufweisen, sondern allen Schülern eine gleichgeartete Allgemeinbildung vermitteln sollte. Schmittleins wiederholte Attacken auf einen zu früh einsetzenden und auf Kosten der lebenden Fremdsprachen zu intensiv betriebenen Latein- und Griechischunterricht ${ }^{126}$ fanden im Plenum allerdings keine ungeteilte Zustimmung. Die Reformkommission votierte mehrheitlich für die Beibehaltung eines altsprachlichen $Z$ weiges und gegen eine Reduzierung des Lateinunterrichts zugunsten des Französischen ${ }^{127}$.

Auch zur Frage der schulischen Prüfungen nahm Schmittlein dezidiert Stellung, indem er das in Frankreich praktizierte System der Examina scharf kritisierte. Das baccalauréat sollte statt in zwei Etappen auf einmal abgelegt werden, entweder als Schulabschluß- oder als Universitätsaufnahmeprüfung. Er wandte sich zudem gegen die externen, den Schülern unbekannten Prüfungskommissionen und beklagte den Konkurrenzdruck, den das concours-Verfahren erzeugte. Dieselben Mängel konstatierte er für die Universitätsexamina. Nur für die Besetzung der höheren öffentlichen Ämter (die "grandes carrières“) sei das Wettbewerbsprinzip gerechtfertigt, da der Staat das Recht habe, seine Beamten auszuwählen ${ }^{128}$. Diese Thesen polarisierten die Kommission, wobei Vizepräsident Durry zu denen gehörte, die Schmittlein heftig widersprachen, Erziehungskommissar Capitant zu jenen, die ihm beipflichteten. Der Abschluß-

${ }^{124}$ Die geschilderten Grundsātze nach dem Sitzungsprotokoll vom 29.3.1944 und dem „Projet Schmittlein", das umfassender und präziser als die im Protokoll wiedergegebene Stellungnahme Schmittleins ist.

125 Sitzungsprotokoll vom 29.3.1944.

126 Sitzungsprotokolle vom 5.4., 12.4., 19.4. und 26.4.1944.

127 Sitzungsprotokolle vom 24.5. und 31.5.1944. Am Tag der Abstimmung hatte Schmittlein nicht an der Sitzung teilgenommen.

${ }^{128}$ Sitzungsprotokoll vom 21.6.1944. Zum baccalauréat āußerte sich Schmittlein in seinem Memorandum. 
bericht forderte schließlich, das baccalauréat müsse entweder in seinen Anforderungen verschärft und über zwei Jahre hinweg vorbereitet oder durch ein einfaches Schulabgangszeugnis ersetzt werden.

Als diese Fragen in der zweiten Julihälfte 1944 diskutiert wurden, hatte Schmittlein seinen Posten im Stab de Gaulles bereits aufgegeben und sich zu einem militärischen Kommando gemeldet, um an der Befreiung Frankreichs teilzunehmen. Er ahnte wohl kaum, daß die Schulreformpläne, die er mitgestaltet hatte und die in der Tat nicht mehr als eine „provisorische, rohe Skizze“, ein „halboffizielles Dokument“ hervorbrachten ${ }^{129}$ und „selbst in Kreisen französischer Pädagogen wenig bekannt“ wurden $^{130}$, die Grundlagen weiterer Projekte dieser Art bildeten. Während Schmittlein die militärische Rückeroberung seiner späteren Heimatstadt Belfort ${ }^{131}$ im November 1944 miterlebte, berief der inzwischen vom Erziehungskommissar im Exil zum Pariser Minister avancierte René Capitant eine neue Studienkommission, die zunächst unter Leitung des Physikers Paul Langevin, nach dessen Ableben unter Vorsitz des Pãdagogen und Psychologen Henri Wallon eine gründliche Reorganisation des gesamten öffentlichen Bildungswesens erarbeiten sollte. Als deren umfassender Entwurf im Juni 1947 schließlich vorgelegt wurde und zu einer wahren „Charta der Neuen Schule Frankreichs“ avancierte ${ }^{132}$, war die „Philosophie“ der Algier-Kommission zu ihrem logischen und konsequenten Schluß geführt ${ }^{133}$.

Inzwischen stellte sich den Verantwortlichen in Paris die Aufgabe, nicht nur der eigenen Bevölkerung ein neukonzipiertes Erziehungs- und Ausbildungssystem aufzuerlegen, sondern auch die rééducation des besiegten deutschen Volkes, zumindest seines unter französische Besatzung geratenen Teiles, zu organisieren. Daß Capitant bei der Suche nach einer hierfür geeigneten Führungspersönlichkeit auf Schmittlein kam, überrascht nach den bisherigen Darlegungen nicht. Es galt aber, dem designierten $D i$ recteur de l'Education Publique Richtlinien für seine Umerziehungs- und Kulturmission in der französischen Zone an die Hand zu geben. Denn als Schmittlein im Frühjahr 1945 von seiner Ernennung erfuhr, wurde ihm bewußt, wie sehr die Kriegsjahre seine Wahrnehmung des Nachbarlandes verzerrt hatten ${ }^{134}$. Daß er wenige Monate später mit einem ,sehr präzisen, seit 1943-44 in Algier ausgearbeiteten Aktionsprogramm “ in Baden-Baden angekommen sei $^{135}$, erscheint demnach wenig wahrscheinlich. Immerhin waren unterdessen Überlegungen angestellt worden, wie die Deutschen auf den rechten demokratischen und friedfertigen Weg zurückzubringen seien.

129 Miles, Recent Reforms, S. 55.

130 Honig, Schulreformen, S. 152.

${ }^{131}$ Nach seiner Rückkehr aus Deutschland 1951 ließ sich Schmittlein in Belfort nieder. Diesen Wahlkreis vertrat er als gaullistischer Abgeordneter in der Pariser Nationalversammlung; hier übernahm er kommunalpolitische Ämter und gab eine Zeitung heraus. In einer alten Mühle nahe Belfort verbrachte er schließlich seine letzten Lebensjahre.

132 Schneider, Neue Erziehung, S. 87.

133 So Miles, Recent Reforms, S. 55.

$134 \mathrm{Vgl}$. Schmittlein, Souvenirs; gefunden in: AOFA, AC 31,1.

135 So Robert Marquant, in: Hochschuloffiziere, S. 24. Diese These beruht auf der nicht erwiesenen Annahme, in Algier seien Schulreformpläne auch für Nachkriegsdeutschland entwickelt worden. 


\section{2. „Was tun mit Deutschland?“ - „Die Deutschen umerziehen"!?}

Schon bald nach dem Eintritt ihrer Nationen in den Zweiten Weltkrieg entbrannte in politischen, wissenschaftlichen und publizistischen Kreisen Großbritanniens und der Vereinigten Staaten eine lebhafte, kontrovers geführte Diskussion über Sinn und Zweck, Möglichkeiten und Grenzen einer re-education, der ,geistigen Demokratisierung" des deutschen Volkes nach dem erhofften Sieg über Hitlers Armeen ${ }^{136}$. Im Oktober 1942 konstituierte sich auf britische Initiative in London eine alliierte Konferenz der Erziehungsminister aus zehn zumeist von Deutschland besetzten europäischen Staaten, um über Nachkriegsprobleme im Bildungsbereich zu beraten ${ }^{137}$. Die Umerziehungsfrage wurde zunächst ausgeklammert; erst im August 1944 stand sie schließlich auf der Tagesordnung. Delegationsleiter des Freien Frankreich war Paul Vaucher, Geschichtsprofessor und vormals Mitglied der Section intellectuelle et de l'enseignement in de Gaulles Planungskommission. Er berichtete aus London, daß alle Beteiligten deutliche Vorbehalte hinsichtlich der Wirkungschancen einer Umerziehung angemeldet hätten. Sein Landsmann Vermeil habe es als Ungerechtigkeit bezeichnet, deutsche Universitäten wiederzueröffnen, solange die von Wehrmachtstruppen zerstörten Hochschulen in anderen Ländern nicht wieder funktionstüchtig seien ${ }^{138}$.

Drei Tage nach dieser Konferenz und ihre Ergebnisse vermutlich mit berücksichtigend, verfaßte de Gaulles politischer Berater Maurice Dejean ein vertrauliches Memorandum zum "problème allemand“. Besonders in angelsächsischen Kreisen, hieß es darin, sei oft von der Erziehung Deutschlands die Rede, in deren Überwachung manche einen wichtigen Faktor europäischer Sicherheit sähen. Solche Maßnahmen könnten vielleicht nützlich sein, für lange Zeit aber allenfalls ein „zusätzliches Element“ der französischen Deutschlandpolitik darstellen. Keinesfalls dürften sie militärische und ökonomische Garantien ersetzen. In Wirklichkeit gehe es weniger um Erziehungsfragen als um die rééducation eines ganzen, von falschen Propheten und mit verlogenen Doktrinen vom rechten Wege abgebrachten Volkes, das vor allem unschädlich gemacht und in diesem Zustand gehalten werden müsse ${ }^{139}$. Ähnlich nüchternskeptisch sah zur selben Zeit Edmond Vermeil die Dinge. Im November 1944 führte er aus, daß die Umerziehung der Deutschen - verstanden als tiefgreifender Wandel ihrer Mentalität, als Heilung vom großdeutschen Wahn - ein äußerst schwieriges, jedoch lebensnotwendiges Unterfangen sei, von dem Frankreichs Schicksal abhänge. Ein solches Vorhaben erschien ihm allerdings nur in dem Maße erfolgversprechend, wie sich die Mehrheit der deutschen Bevölkerung unter dem Eindruck eines katastrophalen

${ }^{136}$ Hierzu Bungenstab, Umerziehung; Lange-Quassowski, Neuordnung; Tent, Mission; Pakschies, Umerziehung; Halbritter, Schulreformpolitik; Lutzebäck, Bildungspolitik; Heinemann (Hrsg.), Umerziehung und Wiederaufbau; Pronay/Wilson (Eds.), Political Re-Education.

137 Vgl. Allied Plan for Education, S. 1f.; Pakschies, Umerziehung, S. $55 \mathrm{f}$.

${ }^{138}$ MAE, Z/Allemagne/99, fol. 17f., Massigli an Bidault am 25.6.1945 (Das Außenministerium hatte den Botschafter in London um eine Dokumentation über die britischen Umerziehungspläne gebeten); vgl. auch Cuer, L'action culturelle, S. 15; zu Vaucher Who's Who in France, 1957/58, S. 2215.

139 MAE, Y/Allemagne/278, fol. $19 \mathrm{ff}$., Dejeans Memorandum „Le problème allemand“ vom 21.8.1944. 
Zusammenbruchs und einer unnachsichtigen, solidarischen Haltung der siegreichen Besatzungsmächte zur spontanen Selbstreinigung fähig zeige. „Die Umerziehung Deutschlands, die auf die freiwillige Zustimmung (adhésion) der Deutschen zu einem internationalen Verhaltenskodex (morale) abzielt, und die Übereinstimmung der Alliierten hinsichtlich dieses pädagogischen Unterfangens sind die unabdingbare Voraussetzung für den Erfolg des künftigen Völkerbunds.“ Dabei setzte Vermeil dem „soliden Optimismus“ der Angelsachsen, die ohne Selbstzweifel den Deutschen „das wahre soziale, demokratische und moralische Evangelium“ zu bringen trachteten, seine pessimistisch-fatalistische Geschichtsauffassung über die „traditionelle Aggressivităt Deutschlands gegenüber dem westlichen Humanismus“ entgegen ${ }^{140}$.

Angesichts solcher Skepsis bei maßgeblichen politischen und intellektuellen Mitarbeitern des Freien Frankreich überrascht es kaum, daß konkrete, umfassende Pläne zur rééducation der Deutschen in Kreisen der Provisorischen Regierung lange Zeit ausblieben ${ }^{141}$. Die von de Gaulle im Londoner Exil eingerichtete Section intellectuelle et de l'enseignement hatte auf die Entwicklung eines eigenen Umerziehungskonzepts gänzlich verzichtet und sich statt dessen die Option einer Übernahme alliierter Vorarbeiten offengehalten ${ }^{142}$. Auch in der Algier-Kommission des Jahres 1944 stand das Thema rééducation nicht auf der Tagesordnung. So ist es wenig erstaunlich, daß Schmittlein im Früjahr 1945 noch keine offiziellen Richtlinien erhielt. Im Pariser Außenministerium war man zum damaligen Zeitpunkt der Ansicht, daß die in Deutschland zu verfolgende Bildungspolitik auf wenige Grundprinzipien hinauslaufe. Was hierzu in einer stark an Vermeil gemahnenden Aufzeichnung dargelegt wurde, war denn auch lakonisch: ein Satz zu den Grundschulen, zwei Sätze bezüglich der Gymnasien, drei schließlich zu den Universitäten und deutschen Auslandsinstituten. Zweck der Maßnahmen sei es, der Schuljugend das Verstāndnis für menschliche Freiheit und Persönlichkeit, internationale Moral und humanistischen Geist zu vermit$\operatorname{tel}^{143}$. Ausführlichere Vorgaben der Pariser Regierung für Schmittleins inzwischen errichtete Erziehungsbehörde in Südwestdeutschland ließen bis November 1945 auf sich warten.

Die französische Exil- und Résistancepresse griff hingegen schon während des Krieges, nicht zuletzt unter dem Eindruck der angelsächsischen Diskussion, vereinzelt die Idee einer rééducation des nationalsozialistischen Deutschlands auf. In der Bewertung dieser Frage spiegelten sich grundsätzliche, oft weltanschaulich fundierte Meinungsverschiedenheiten unter den gegen Vichy und die Besatzungsmacht kämpfenden Franzosen wider. So herrschte Uneinigkeit über die künftig gegen das Reich zu ergreifenden Sicherheitsmaßnahmen: ein neues, härteres „Versailles“ oder - im Gegenteil - der Verzicht auf ähnlich verhängnisvolle Bestimmungen? Territoriale Aufsplitterung, Gebietsamputationen, Annexionen, Reparationen - oder nichts von alledem, sondern eine gesamteuropäische, föderative Friedenslösung? Idealtypisch und grob schematisiert, standen sich das „Dominanzkonzept“ de Gaulles, das ähnlich von

140 Vermeil, Le problème allemand, S. 75 ff.; vgl. Auerbach, "Que faire“, S. $290 \mathrm{f}$.

141 Aufschlußreich hierfür ist das Vorwort in Vermeil et al., Quelques aspects, S. $12 \mathrm{f}$.

142 MAE, Guerre 1939-45, Londres, CNF/186, fol. 26 ff., 86, 119.

143 MAE, Z/Allemagne/99, fol. 1 f., Aufzeichnung der Nordeuropaabteilung für den Außenminister, vermutlich vom April 1945 (undatierte Durchschrift), „Problème de la rééducation dans la zone d'occupation française". 
den Kommunisten vertreten wurde, und das „Integrationskonzept“ der nichtkommunistischen Résistance gegenüber ${ }^{144}$. Die Realität war selbstverständlich komplexer, uneinheitlicher.

So schwierig sich eine gerechte Beurteilung der außergewöhnlichen, facettenreichen Persönlichkeit Charles de Gaulles erweist ${ }^{145}$, so unzweifelhaft muß doch seine außenpolitisch-machtstaatliche Vorstellungswelt der nationalistischen Tradition, allerdings mit deutlich pragmatischen Zügen, zugeordnet werden ${ }^{146}$. Aus klerikal-monarchistischem Elternhause stammend, am Jesuiten-Collège und an der Militärakademie erzogen, vom Gedankengut der Action française Maurras' und Bainvilles beeinflußt, huldigte de Gaulle einem Frankreichbild, in dem nationale Größe und Integrität des Empire, Macht und internationaler Rang des Vaterlandes die Schlüsselkategorien darstellten $^{147}$. Dachte er an Deutschland, so beherrschte ihn lange Zeit die Vorstellung von der „Erbfeindschaft" zwischen "Galliern und Germanen“, die sich, mit unterschiedlichen Nationalcharakteren ausgestattet, in einer geostrategisch bedingten Frontstellung zueinander befanden ${ }^{148}$. Für ihn gab es in der historischen Entwicklung keine widerstreitenden „deux Allemagnes“, sondern „la malfaisance chronique du germanisme“, das „ewige Deutschland“, das im nationalsozialistischen Staat seine äußerste, perfekte Ausformung gefunden habe. Es genüge daher nicht, den Nazismus auszurotten; vielmehr müßten die Deutschen an sich dauerhaft daran gehindert werden, noch einmal die Nachbarn zu überfallen und die Welt in einen Krieg zu stürzen ${ }^{149}$. „Plus de Reich centralisé!“ lautete de Gaulles Credo, mit dem er glaubte, die „boches“ an einer Rückkehr zu ihren „schlechten Instinkten“ hindern zu können ${ }^{150}$. Wirkungsvolle territoriale Bestimmungen und materielle Reparationsleistungen, die komplementäre Forderung nach „Sicherheit und Kohle"151, bildeten die beiden Pfeiler seiner Deutschlandpolitik als Regierungschef in den anderthalb Jahren nach der Libération. Der von anderen erörterte Aspekt, zur künftigen Sicherheit Frankreichs durch Umerziehung der Deutschen beitragen zu wollen, spielte in den persönlichen Überlegungen des Generals während der Kriegsjahre offensichtlich keine Rolle.

Auf der entgegengesetzten Seite des ideologischen Spektrums, bei Frankreichs Kommunisten, hatte sich in der Kriegszielfrage eine Position herauskristallisiert, die manchen Vorstellungen de Gaulles sehr nahe kam. Nach einer Phase selbstverschuldeter Marginalisierung und Isolation, zwischen Hitler-Stalin-Pakt und deutschem Angriff auf die Sowjetunion, waren die Kommunisten im Untergrund und Exil seit Juni

144 Vgl. Loth, Die Franzosen, S. 28 ff.; Ziebura, Deutsch-französische Beziehungen, S. 24 ff.

145 Vgl. z. B. De Gaulle en son siècle.

146 Loth weist darauf hin, daß sich de Gaulles „Spielart des Nationalismus [...] vom integralen Nationalismus eines Charles Maurras dadurch [unterschied], daß sie einerseits auch transnationalen Wertbegriffen wie dem Begriff der Freiheit oder der europäischen Zivilisation verpflichtet war, und daß er andererseits durchaus ein Gespür für die Entwicklung machtpolitischer Realitäten besaß“; Die Franzosen, S. 30. Vgl. die jüngste und umfassendste Biographie von Lacouture, De Gaulle.

147 Vgl. de Gaulles Schriften: Le fil de l'épée; Vers l'armée de métier; La France et son armée.

148 Eine knappe, treffende Zusammenfassung seines Frankreich- und Deutschlandbildes bei Marcowitz, Grundzüge.

149 Zitiert nach Michel, Les courants, S. 88. Vgl. auch Lipgens, Bedingungen.

150 De Gaulle, Memoires de guerre, t. III, S. 57.

${ }^{151}$ So Korff, Le revirement, S. 79, im Anschluß an Willis, The French, S. $32 \mathrm{ff}$. 
1941 um so intensiver bemüht, sich als entschlossenste Widerstandskämpfer zu profilieren ${ }^{152}$. Nachsicht mit den Deutschen lehnten sie zunächst entschieden ab. Allmählich nahmen sie aber - der sowjetischen Linie entsprechend - die Unterscheidung zwischen „Hitlerfaschismus“ und deutscher Bevölkerung wieder auf, nun allerdings mit dem Zusatz, die Mehrheit des Nachbarvolkes habe sich zu Komplizen der Nazigangster gemacht und sei entsprechend zu behandeln ${ }^{153}$. Wie viele Gaullisten standen sie einer rééducation, in die Sozialisten und Christdemokraten einige Hoffnung setzten, mit großer Skepsis gegenüber. In ihren vernichtenden „Bemerkungen“ zum sozialistischen Projekt eines gemeinsamen Résistance-Programms bezeichnete die KPFFührung im April 1944 eine Umerziehung als vage konzipiertes, schwierig zu realisierendes Unterfangen, dessen Wirksamkeit zu bezweifeln sei ${ }^{154}$. Sie setzte demgegenüber auf eine grundlegende sozioökonomische Umwälzung der deutschen Verhältnisse und propagierte im Bereich der Außenpolitik eine neue europäische Ordnung, innerhalb derer Frankreich nur im festen Bündnis mit der Sowjetunion die deutsche Gefahr bannen könne. Auch in ihrem Mißtrauen gegenüber den amerikanischen Absichten und der als Hauptsorge ausgegebenen Bewahrung der Einheit und Größe Frankreichs fanden sich Kommunisten und Gaullisten in einer bemerkenswerten Allianz $^{155}$. Allerdings näherten sich seit Frühjahr 1942 die Mitstreiter de Gaulles und der nichtkommunistischen Résistance in wichtigen Fragen einander an, so daß angesichts der nationalen Notlage ein republikanischer Kriegsgaullismus auf breiter Grundlage entstand. Meinungsverschiedenheiten in konzeptionellen und taktischen Fragen, persönliche Querelen zwischen Widerstandsgruppen oder deren Chefs sowie zwischen ihnen und der Entourage de Gaulles in London bzw. Algier blieben allerdings bis zur Libération und darüber hinaus bestehen ${ }^{156}$.

Hinsichtlich der deutschen Frage zeigte sich insofern ein übergreifender Konsens, als auch die Angehörigen der mouvements mehrheitlich eine strenge Bestrafung der für den Krieg Verantwortlichen, eine dauerhafte Besetzung des Nachbarlandes sowie die Ausschaltung seiner mächtigen Militärmaschinerie und des bedrohlichen deutschen Industriepotentials für unabdingbar hielten ${ }^{157}$. Ansonsten konnten die Meinungen selbst innerhalb einer politisch-weltanschaulichen „Familie“ weit auseinandergehen. Im Juni 1943 wollte beispielsweise die sozialistisch geprägte Libération (Nord) keine Unterscheidung zwischen dem deutschen Volk und seinen Führern treffen. Sie bezeichnete die innerdeutsche Opposition als zwar mutige, aber verschwindend kleine Minderheit, proklamierte eine kollektive Verantwortlichkeit Deutschlands und forderte die Franzosen auf, Lehren aus der jüngeren Geschichte, dem trügerischen, weil

152 Zur Geschichte der KPF während des Zweiten Weltkrieges vgl. Azéma/Prost/Rioux (Eds.), Le P.C.F. Die partielle UUbereinstimmung zwischen Gaullisten und Kommunisten, z. B. hinsichtlich des Nationalismus, verleitet Gegner beider Lager zu Schlußfolgerungen, die oft an Verschwörungstheorien erinnern, zuletzt Giraud, De Gaulle.

153 Zusammenfassende Darstellung bei Michel, Les courants, S. 707 f.

$154 \mathrm{Vgl}$. Michel/Mirkine-Guetzévitch, Les idées politiques, S. $218 \mathrm{ff}$., hier S. 234.

155 Vgl. Michel, Les courants, S. $709 \mathrm{f}$.

156 Zur Entwicklung des Verhältnisses zwischen France Libre und innerer Résistance vgl. ebenda, S. $56 \mathrm{ff} ., 93 \mathrm{ff} ., 222 \mathrm{ff}$. und $726 \mathrm{ff}$;; Moulin et le C.N.R.; zusammenfassend Knipping, "Réseaux" und „Mouvements".

157 Vgl. Michel, Les courants, S. $412 \mathrm{ff}$. 
zu nachsichtigen Waffenstillstand der Zwischenkriegszeit zu ziehen ${ }^{158}$. Zur selben Zeit gab die ebenfalls sozialistische Zeitung „Le Populaire“ die konträre Meinung des Parteichefs Léon Blum wieder: Rachegelüste gegenüber dem deutschen Volk und Forderungen nach einer endgültigen Ausschaltung dieser Bedrohung seien zwar verständlich und gerechtfertigt, jedoch lasse sich historisch belegen, daß man $\mathrm{Haß}$ nicht mit Haß, Gewalt nicht mit Gewalt besiegen könne. Das einzige Mittel, Deutschland unschädlich zu machen und ein friedliches, sicheres Europa zu schaffen, bestehe darin, das Nachbarland in eine Staatengemeinschaft zu integrieren, die stark genug sein müsse, es umzuerziehen, zu disziplinieren, gegebenfalls zu bändigen ${ }^{159}$. Noch prāgnanter läßt sich die heterogene, spannungsreiche Bandbreite des „revolutionären $\mathrm{Hu}$ manismus", der als Hauptcharakterzug der nichtkommunistischen Résistance und wichtigstes Unterscheidungsmerkmal gegenüber den Vorstellungen der nationalistischen Rechten und Linken gelten $\mathrm{kann}^{\mathbf{1 6 0}}$, anhand eines Artikels veranschaulichen, der im März 1944 in „Combat“ erschien. Sein Verfasser war Claude Bourdet, Repräsentant der Südzone im Zentralkomitee der vereinigten Widerstandsgruppen und später linkssozialistischer Abgeordneter in der Pariser Nationalversammlung ${ }^{161}$. Der revolutionäre Geist des Widerstands, hieß es da, wende sich dem künftigen Europa zu, das nicht ohne Deutschland aufzubauen sein werde. Weder humanitäre Sentimentalität noch kleinbürgerlicher Sadismus vertrügen sich mit einer solchen Einstellung. Das System von Versailles, das allein dem internationalen Kapitalismus gedient habe, sei letztlich für den Nationalsozialismus verantwortlich. Zugleich reprāsentiere dieser die „letzte Inkarnation des germanischen Größenwahns, der vom zusammenbrechenden Kapitalismus ausgenützt und - wie seit eh und je - der Disziplin des preußischen Militarismus untergeordnet wurde“. Es gelte nun, Deutschland „politisch wie kulturell für eine Reihe von Jahren unter Vormundschaft zu stellen“. Doch müßten auch alle anderen europäischen Nationen zugunsten einer kontinentalen Föderation auf einen Teil ihrer Souveränitāt verzichten. Allein dieser europäische Staatenbund werde das moralische Recht besitzen, „darüber zu wachen, daß in Deutschland - wie anderswo die Kinder zur Achtung vor dem Menschen und zum Haß gegen die Unterdrückung erzogen werden“162.

Wie sollte aber eine „neue Erziehung“ im Nachkriegsdeutschland aussehen? Erste Úberlegungen hierzu stellte im November 1943 Francis Gérard in Algier zur Diskussion, als er die Frage aufwarf: „Que faire de l'Allemagne?" ${ }^{\text {163 }}$ Im deutschen Bildungs-

158 „Libération (Nord)“, No. 135, 29.6.1943, abgedruckt in: Michel/Mirkine-Guetzévitch, Les idées politiques, S. $379 \mathrm{f}$. Vgl. zu Libération (Nord) auch Lipgens, Europa-Föderationspläne, S. 180 .

159 „Le Populaire (Edition zone-sud)“, Juli 1943, abgedruckt in: Michel/Mirkine-Guetzévitch, ebenda, S. $380 \mathrm{f}$. Vgl. auch Blum, A l'échelle humaine, in: L'CEuvre, S. $408 \mathrm{ff}$, sowie seine "Mahnung aus dem Gefängnis" vom 5.2.1943, in: Lipgens, Europa-Föderationspläne, S. $199 \mathrm{ff}$.

160 Vgl. Lipgens, Innerfranzösische Kritik; Ziebura, Deutsch-französische Beziehungen, S. $26 \mathrm{ff}$.; Trouillet, Deutsch-französisches Verhältnis, S. 259.

$161 \mathrm{Zu}$ Bourdets Rolle im Widerstand vgl. Hostache, Le Conseil National, S. 147f. und $216 \mathrm{f}$

162 Wiedergegeben in: Ziebura, Idee, S. 372 f; ders., Deutsch-französische Beziehungen, S. 29f.; Lipgens, Europa-Föderationspläne, S. $237 \mathrm{f}$.

163 Gérard, Que faire; Auszüge in: Lipgens, ebenda, S. $218 \mathrm{ff}$. Der 1929 in Frankreich naturalisierte Deutsche Gérard ist von Ruge-Schatz wohl zurecht mit Combat in Verbindung ge- 
wesen hielt Gérard eine strenge Kontrolle für unerläßlich. Er redete, vermutlich unter dem Eindruck der innerfranzösischen Schulreformbestrebungen, der Einheitsschule das Wort, plädierte für das staatliche Unterrichtsmonopol und wollte alle Lehrkräfte, die sich als "créatures du pangermanisme“ erwiesen hatten, aus dem Dienst entfernt sehen. Am Ende seiner knappen Darlegungen zum Erziehungsbereich stellte er fest, daß man fast überall die Kinder zum Objekt politischer, religiöser und weltanschaulicher Interessenkonflikte degradiert habe. Nun müsse - in Deutschland wie anderswo - die Humanität wieder zur alleinigen Bildungsgrundlage erhoben werden ${ }^{164}$.

„Was tun mit Deutschland?" Über dieses Problem dachte im April 1945 auch Pierre Grappin nach ${ }^{165}$. Der junge Germanist, der kurz darauf als chargé de mission dem Leiter der Militärregierung in Baden-Baden zugeteilt wurde, umriß in einer Broschüre seine Vorstellungen zur Umerziehung folgendermaßen: Es handle sich um nichts Geringeres als die Formung einer neuen Generation von Menschen. Wenngleich es naiv wäre, den Deutschen von außen ein Standardmodell der Demokratie nach amerikanischem Muster verordnen zu wollen, so dürfe man doch die Hoffnung nicht aufgeben, daß das Nachbarvolk eines Tages nach demokratischer Façon leben werde. Bis dahin müsse man mit allen Mitteln die demokratische Erziehung der Jugend fördern, vertrauenswürdiges Unterrichtspersonal ausfindig machen und gleichzeitig neue Generationen von Lehrkräften heranbilden. Schließlich gelte es, den Geist der Universitäten zu verändern, indem man jene Disziplinen ausschalte, die in den Dienst nationalistischer Politik gestellt worden waren, und die Liebe zu echter Wissenschaft und Bildung wiedererwecke. Grappin baute ganz auf die deutsche Jugend; die meisten Erwachsenen über 30 Jahre gab er für ein Umerziehungsprogramm verloren. Frankreich könne während längerer Zeit wohl nur auf Minderheiten im Nachbarland setzen, denen gegebenenfalls Sondervollmachten zu übertragen seien. Schließlich betonte er, in Deutschland werde sich, mehr als anderswo, eine Demokratie nur im Zuge tiefgreifender sozialer Veränderungen entwickeln, wobei Grappin vor allem an einen langfristigen Einstellungswandel dank demokratisierter Bildungseinrichtungen dachte $^{166}$. In dieser programmatischen Schrift finden sich wesentliche Prämissen der wenig später in Baden-Baden verfügten Bildungspolitik: der Glaube des Pädagogen an die Modellierbarkeit der Menschen ${ }^{167}$; die stillschweigende Annahme, eine "Demokratisierung des Denkens“ werde gleichsam automatisch zur politischen Demokratie führen; die Überzeugung, Frankreich müsse, um effektiv zu sein, seine Kontrollfunktion mindestens über den Zeitraum einer Generation, also 25 bis 30 Jahre lang, ausüben; schließlich die kritische Distanz gegenüber angelsächsischen Vorstellungen. Zu ähnlichen Einschätzungen wie Grappin gelangte im übrigen auch Schmittlein als $D i$ recteur de l'Education Publique in der französischen Besatzungszone.

\section{Fortsetzung Fußnote von Seite 44}

bracht worden; Grundprobleme, S. 93; vgl. auch den Hinweis auf Gérards Autorenschaft in der surrealistischen Revue „L'Oeuf dur“ Mitte der 20er Jahre bei Trebitsch, Le groupe „Philosophies“, S. 31.

164 Vgl. Gérard, Que faire, S. 73 ff. Das Plädoyer der Widerstandsgruppen für die politische Neutralität der französischen Schulen kommt auch zum Ausdruck bei Hauriou, Vers une doctrine, S. 62.

165 Grappin, Que faire.

166 Vgl. ebenda, S. 30 f.; Auerbach, „Que faire“, S. 289 und 293.

167 Darauf verweist Cheval, Education, S. 115. 
Am ausführlichsten beschäftigte sich in Frankreich eine Frau mit dem Problem der Umerziehung Deutschlands: Sarah Claire Boas de Jouvenel, die sich als Autorin hinter dem Pseudonym „Ariel“" verbarg ${ }^{168}$. Wie viele französische und angelsächsische Zeitgenossen interpretierte sie den Nationalsozialismus als „vorübergehende Erscheinung (accident provisoire) in der Dauerkrankheit der deutschen Seele“. Daher genüge es nicht, diese Ideologie auszurotten; vielmehr müsse die kranke deutsche Seele „entwikkelt" und diskret gelenkt werden ${ }^{169}$. Wenngleich die Umerziehung im Prinzip alle Lebensbereiche und Bevölkerungsgruppen betreffen sollte, empfahl Ariel eine differenzierte Dosierung. Im Gegensatz zu Grappin forderte sie gerade für die deutsche Jugend - "la fleur du nazisme“ - die unnachsichtigste Behandlung, beispielsweise in Arbeits- und Umerziehungslagern außerhalb des eigenen Landes ${ }^{170}$. Dennoch erhob die Verfasserin den Versöhnungsgedanken zum Leitmotiv ihres detaillierten Programms $^{171}$. Auch befürwortete sie ein indirektes, taktvolles Vorgehen, um bei den Deutschen nicht das Gefühl aufkommen zu lassen, von Fremden missioniert zu wer$\operatorname{den}^{172}$. Der Vorbildfunktion ihrer Landsleute räumte „Ariel“ einen hohen Stellenwert $e^{173}$. Nicht nur über Methoden der Umerziehung, sondern auch über die Organisationsstrukturen der künftigen Besatzungsverwaltung in Deutschland stellte die Autorin bemerkenswerte Úberlegungen an. Während sie im Schulwesen des Nachbarlandes tiefe Eingriffe als notwendig erachtete, vertrat sie hinsichtlich der übrigen erziehungs- und kulturpolitischen Sektoren den Grundsatz größtmöglicher Liberalität und Flexibilität ${ }^{174}$. Doch ungeachtet der Versöhnungsbereitschaft und der christlich-missionarischen Elemente ${ }^{175}$ war Ariels Programm beileibe kein reines Manifest der Nächstenliebe. Frankreichs Sicherheit stand am Anfang aller Úberlegungen, Deutschland umzugestalten, die „deutsche Seele wiederzuerwecken“, das „explosive Gebräu“ jenseits des Rheins zu entschärfen ${ }^{176}$. Im Grunde hatte Madame de Jouvenel keine gute Meinung von den Deutschen, die eine Nation darstellten, bei der man a priori keine gefestigten sittlichen Grundsätze erwarten dürfe. Hier sei zunächst eine „occupation morale“ vonnöten ${ }^{177}$. „Wollen wir den Frieden? Nun, dann gestalten wir die Deutschen um“, lautete im Frühjahr 1945 „Ariels“ Aufforderung an die Franzosen ${ }^{178}$. Auch Madame de Jouvenels Gedanken - soviel sei vorweggenommen - können in ihren Hauptprämissen und -implikationen als typisch für Motivationen und Handlungen der Kultur- und Bildungspolitiker im Nachkriegsdeutschland gelten. Versöhnungsbereitschaft aus Einsicht in die europäische Schicksalsgemeinschaft, aber auch aus Interesse an Deutschland, hochfliegender Idealismus und Einfallsreichtum, ein

${ }_{168}$ Ariel, Rééduquer. Zur Aufdeckung des Pseudonyms: Coston, Dictionnaire des pseudonymes. $\mathrm{Vgl}$. ferner Ariel, Quelques règles (dem Sohn Bertrand gewidmet). Bertrand de Jouvenel wiederum widmete seine Memoiren dem Andenken der Mutter.

$169 \mathrm{Vgl}$. Ariel, Rééduquer, S. $106 \mathrm{f}$.

$170 \mathrm{Vgl}$. ebenda, S. $109 \mathrm{ff}$.

171 Vgl. ebenda, S. 108 und $115 \mathrm{ff}$.

172 Vgl. ebenda, S. 114.

173 Vgl. ebenda, S. 106 und 120.

174 Vgl. ebenda, S. $115 \mathrm{ff}$.

17 Vgl. ebenda, S. 100, 113, 120, 126.

176 Ebenda, S. $11 \mathrm{f}$.

177 Ebenda, S. $93 \mathrm{f}$.

178 Ebenda, S. 12. 
Missionierungsdrang, der sich bei manchem mit dem Bewußtsein französischer Superiorităt verband - diesen Elementen begegnet man beim Versuch einer Rekonstruktion der Zeitumstände auf Schritt und Tritt. Der Kontrast zur Skepsis der „Realpolitiker" ist jedenfalls frappierend.

Ebenfalls schon 1945 nahm sich die Zeitschrift „Esprit“ des Themas Umerziehung an. Ihr Gründer und Herausgeber, der katholische Philosoph und Publizist Emmanuel Mounier, bestritt vehement die so oft behauptete Existenz eines „ewigen“ Deutschlands, dessen nationalistischer Extremismus eine „völkische“ Eigenheit, historisch unveränderlich und grundlegend verschieden von dem in anderen Staaten sei ${ }^{179}$. Fünf Monate nach Deutschlands Kapitulation nahm er einen Artikel mit dem Titel „L'Allemagne de nos mérites" in seine Zeitschrift auf, dessen Autor Joseph Rovan, soeben aus dem KZ Dachau freigekommen, Frankreichs Verantwortung am weiteren Schicksal des Nachbarlandes anmahnte und sich unter anderem für einen deutsch-französischen Jugendaustausch einsetzte ${ }^{180}$. Rovan, stellvertretender Generalsekretär der neugegründeten Volksbildungsorganisation Peuple et Culture, ging 1947 als Mitarbeiter Schmittleins nach Baden-Baden und verkörperte so das Bindeglied zwischen dem Bemühen der Besatzungsmacht um Deutschlands Umerziehung und dem Streben nach kultureller Erneuerung in Frankreich selbst. Diese Strömung für eine breit angelegte culture populaire muß als weiteres Element der Grundlagen französischer Kulturpolitik in Deutschland nach 1945 berücksichtigt werden.

\section{Die französischen Jugend- und Volksbildungsbewegungen bis zur Gründung von Peuple et Culture (1945)}

\section{Drei Hauptströmungen}

Fortschrittlich und reformerisch gesinnte Persönlichkeiten aus dem demokratischen Bürgertum, praktizierende Katholiken, die sich den sozialen Problemen ihrer Zeit öffneten, und die Organisationen der Arbeiterbewegung ergriffen an der Wende zum 20. Jahrhundert Initiativen zur Popularisierung von Wissen und Bildung. Diese drei Tendenzen beherrschten fortan das Feld der nach- bzw. außerschulischen Jugend- und Erwachsenenerziehung ${ }^{181}$. Auch nach der Zäsur von $1914 / 18$ blieb der Dualismus von laizistischen und konfessionellen, zumeist katholischen Einrichtungen bestehen; im übrigen unterlag die éducation populaire in der Zwischenkriegszeit jedoch tiefgreifenden Wandlungsprozessen, deren Hauptcharakteristika sich knapp resümieren las$\operatorname{sen}^{182}$. Das Volksbildungswesen löste sich allmählich von der Vormundschaft der Schulen und Lehrer bzw. der Kirchengemeinden und des Klerus. Junge Menschen gleicher gesellschaftlicher Herkunft oder beruflicher Zugehörigkeit bildeten eigene Vereinigungen, organisierten sich als „Arbeiter- und Bauernkinder“, „Rote Falken“,

179 Vgl. Grosser, Mounier; Moreau, Jugendarbeit, S. 28f.; Trouillet, Deutsch-französisches Verhăltnis, S. $265 \mathrm{f}$.

180 Der im Oktober 1945 in „Esprit“ erschienene Artikel ist in deutscher Ubersetzung abgedruckt in: Rovan, Zwei Völker, S. $83 \mathrm{ff}$.

${ }^{181} \mathrm{Zu}$ den Anfängen der französischen Volksbildungsbewegung vgl. Cacérès, Histoire; Léon, Histoire.

182 Das Folgende nach Labourie, 1920-1940, S. $5 \mathrm{ff}$. 
katholische bzw. christliche Arbeiterjugend (JOC), katholische Landjugend (JAC), katholische bzw. christliche Studenten (JEC) etc. Gleichzeitig führten die meisten dieser Gruppierungen in ihren Reihen das Prinzip einer nach Alters- oder Jahrgangsstufen differenzierten Erziehungsarbeit ein. Bestehende Dachverbände auf nationaler Ebene wurden durch die starke Vermehrung partikularer Initiativen gesprengt, ihrer Daseinsberechtigung beraubt, zumindest aber in ihrer Bindekraft geschwächt. Besondere Techniken, neue Medien, wie Filme in den Ciné-clubs, und Praktiken, wie die „aktiven Erziehungsmethoden“, mit deren Hilfe das Aufsichtspersonal von „Ferienkolonien“ erholungssuchender Kinder geschult wurde, fanden erstmals Anwendung in der Bildungsarbeit. Die Pfadfinderbewegung Baden-Powells stieß auch in Frankreich auf Resonanz und zunehmende Nachahmung, nicht nur in Gestalt verschiedener laizistischer und konfessionell gebundener Pfadfindergruppen, sondern auch bei den Nachwuchsorganisationen politischer Parteien, die sich an den Methoden der Eclaireurs und Scouts orientierten, sie übernahmen und nach ihren Bedürfnissen variierten ${ }^{183}$. Jugendherbergen als Anlaufstellen und Treffpunkte natur- und wanderbegeisterter Jugendlicher erlebten um 1930 eine Gründungswelle. Auch auf diesem Feld, auf dem nicht zuletzt deutsche Einflüsse ihre Früchte trugen ${ }^{184}$, konkurrierten weltliche mit katholischen Verbänden, erblickten aber auch Ausnahmeerscheinungen wie das im südostfranzösischen Contadour beheimatete Comité des auberges du Monde Nouveau das Licht der Welt. Begründer und umschwärmter Mittelpunkt dieses Komitees war der Schriftsteller Jean Giono, dessen literarisches Werk ein Leben in Naturverbundenheit und Friedensliebe pries und nicht wenige junge Leute - unter ihnen Joseph Rovan - zu faszinieren verstand ${ }^{185}$. Zwischen 1933 und 1936 hatten die Schlagworte „Freizeitgestaltung für jedermann (loisir populaire)“ und „Volkskultur“ ihre Hochkonjunktur und drängten den Begriff der außerschulischen „Erziehung“ in den Hintergrund. Schließlich schalteten sich in den 30er Jahren zahlreiche bekannte Intellektuelle und Künstler in die breitenorientierte Kulturvermittlung ein, um die Privilegien einer geistigen Elite zu durchbrechen. Insbesondere in den Reihen und im Umfeld der kommunistischen Partei entstand seit etwa 1934 eine „Neue Kulturelle Politik“186 Volksbildungsinitiativen und politische Volksfront schlossen voller Euphorie einen hoffnungsvollen Bund, der beiden Seiten einen freilich nur kurzen Höhenflug bescherte.

\section{Volksfront - Volkskultur}

Mit dem Wahlsieg der vereinigten Linksparteien im Jahre 1936 schien zunächst eine Ära staatlich garantierter, nutzen- wie erholungbringender Freizeitgestaltung für jeder-

183 Zusammenfassende Darlegung der Ziele und Methoden der Pfadfinderbewegung bei Joubrel, Le Scoutisme, S. $8 \mathrm{ff}$.

${ }^{184}$ Auf deutsche Vorbilder, insbesondere im Bereich katholischer Jugendgruppen der 20er Jahre, verweisen Coutrot, Entre-deux-guerres, S. 33, sowie die Diskussionsbeiträge von Auclaire und Bjornson-Langen in: Les Cahiers de l'Animation, No. 32, S. $90 \mathrm{ff}$.

185 Hierzu Krebs, La paix, S. 173 ff.; Gaudibert, Réflexions, S. 77 ff. Zur Faszination Gionos vgl. Rovans Diskussionsbeitrag in: Les Cahiers de l'Animation, No. 32, S. $88 \mathrm{f}$. Vgl. auch de Mendelssohn, Der Geist, S. 122 ff.

186 Vgl. Ory, L'action culturelle, S. $20 \mathrm{ff}$. 
mann, eine temps des loisirs, anzubrechen ${ }^{187}$. Die materiellen und rechtlichen Voraussetzungen schufen Vereinbarungen, in denen sich Arbeitgeber und Gewerkschaften auf die wirtschaftliche und soziale Besserstellung der Arbeiterschaft, darunter die gesetzliche Einführung des bezahlten Urlaubs und der 40stündigen Arbeitswoche, einigten. Mit Léo Lagrange hielt der erste Staatssekretär für Sport und Freizeit Einzug in ein Pariser Regierungskabinett; sogar ein Comité interministériel des Loisirs wurde gebildet und mit der Erarbeitung einer Gesamtkonzeption betraut. Ob sich hinter dem Front-Populaire-Konzept tatsächlich ein gleichermaßen kultureller wie politischer Entwurf verbarg ${ }^{188}$, mag zwar dahingestellt bleiben. Unbestreitbar ist aber, daß Volksfront und "Volkskultur" in einem engen wechselseitigen Zusammenhang standen, kulturelle Initiativen politisch engagierter Intellektueller und Künstler seit Anfang der 30er Jahre ein für die Bildung der Linkskoalition günstiges Klima miterzeugt hatten. Die pazifistischen, dem Kommunismus nahestehenden Schriftsteller Romain Rolland und Henri Barbusse riefen zu einem Kongreß gegen Krieg und Faschismus auf, zu dem sich im August 1932 zahlreiche Größen des internationalen geistigen Lebens in Amsterdam einfanden. Ebenfalls im Umkreis der KPF entstand die Association des écrivains et artistes révolutionnaires sowie das erste Maison de la Culture in Paris. Das Comité de vigilance des intellectuels antifascistes konstituierte sich nach einem Aufruf des Physikers und nachmaligen Schulreformers Langevin, des einflußreichen Philosophen Alain sowie des Ethnologen, Museumsgründers und späteren sozialistischen Abgeordneten Paul Rivet. Theater, Musik, Filmwelt und Publizistik wetteiferten schließlich in der Erarbeitung „volksnaher“ Werke. So ist das Jahr 1936 mit der „Konvergenz zweier Tendenzen“ treffend charakterisiert worden: „einerseits der kulturellen Bestrebungen eines großen Teils der Arbeiterbewegung, andererseits des Engagements zahlreicher Intellektueller in den Gewerkschaften und linken Parteien“"189.

Welche vielfältigen Aktivitäten die neue Regierung anvisierte, zeigt ein Bericht ihres „Freizeit-Ausschusses“ an den Staatspräsidenten vom Juli 1936: „[...] alles, was mit Sport, Wettkämpfen (fêtes) und anderen sportlichen Veranstaltungen zu tun hat [...]. Förderung von Konzerten und Aufführungen, Museumsführungen mit Begleitvorträgen, von Vereinigungen, die sich dem Chorgesang, der Instrumentalmusik und der Filmkunst widmen. [...] alles, was den Massentourismus (tourisme populaire) und die Jugendherbergen betrifft [...].“190 Nach diesen Vorgaben ging Staatssekretär Lagrange ans Werk. Er förderte den Breitensport und die Popularisierung bislang elitärer Sportarten. In Zusammenarbeit mit den interessierten Verbänden verhalf er dem anwachsenden Wochenend-Exodus der Stadtbevölkerung „hinaus ins Freie“ zu neuen Möglichkeiten und Dimensionen. Tourismus für jedermann, Camping- und Jugendherbergswesen erlebten einen bis dahin unbekannten Boom. „Ferienkolonien“ für Kinder kamen in Mode und machten die Ausbildung von entsprechendem Aufsichtspersonal notwendig. Die hierfür errichteten Centres d'entraînement aux méthodes d'éducation actives wurden ebenfalls subventioniert. Auch die traditionelle Kultur in Theater, Oper und Museen, aus Literatur und Wissenschaft sollte weiten Teilen der Bevölkerung zu-

\footnotetext{
${ }_{187}$ So die Kapitelüberschrift bei Cacérès, Histoire, S. 87. Vgl. zu dieser Phase auch die Großbritannien und Frankreich vergleichende Studie von Cross, Vacations.

${ }^{188}$ Ory, ebenda.

189 Léon, Histoire, S. 177.

190 Zitiert nach Cacérès, Histoire, S. 97.
} 
gänglich gemacht werden. Unkonventionelle Projekte in diesen Bereichen und neue Medien, wie das Filmwesen, erhielten staatliche Unterstützung. Neben solchen Fördermaßnahmen ergriff die Regierung Blum auch selbst die Initiative, indem sie mit Blick auf die größtmögliche Verbreitung wissenschaftlicher Erkenntnisse den Bau zweier didaktisch konzipierter Museen, des Palais de la Découverte und die Einrichtung des Centre National de la Recherche Scientifique (CNRS), in Auftrag gab. Staatlichem Dirigismus in der Kulturpolitik erteilte Lagrange jedoch eine klare Absage: „In unserem Land verträgt sich nichts weniger mit Direktiven - und seien sie noch so liberal (peu autoritaires) - als das Streben nach Kultur. " ${ }^{\text {191 }}$

\section{Zwischen Vichy und Maquis}

Die Euphorie der Linksunion hielt nicht lange an. Spätestens mit dem Sturz des zweiten Volksfrontkabinetts im Frühjahr 1938 zerstoben viele Träume einer die Massen umfassenden Bildungsexpansion, nachdem schon Monate zuvor die Etatmittel für Sports et Loisirs empfindlich gekürzt worden waren. Der deutsche Einmarsch und die Inauguration des autoritär-paternalistischen Vichy-Regimes im Sommer 1940 bedeuteten das Ende für die Mehrzahl jener Initiativen, die mit culture populaire eine linke politische Stoßrichtung verbanden. Marschall Pétain setzte auf die Erziehung der Jugend nach den Losungen des Etat Français: Travail, Famille, Patrie. Sport und berufliche Bildung wurden in diesem Sinne ausgerichtet, das Erziehungswesen von ,intellektueller Schlacke“ befreit ${ }^{192}$. Nicht unähnlich der Entwicklung im nationalsozialistischen Deutschland, wenn auch weniger totalitär, betrieb die Regierung Laval eine Verklärung der Jugend ${ }^{193}$ und bemühte sich, ihre jungen Staatsbürger in Organisationen zu erfassen. Dabei stieß sie zunächst durchaus auf Kooperationsbereitschaft seitens einiger Jugendleiter, die den Einfluß ihrer Gruppen zu erhöhen suchten. Auf ihre Initiative entstanden die Compagnons de France, die in Schulungslagern neue pädagogische Grundlagen und Methoden entwickeln wollten, aber auch konkrete Hilfestellung in Fragen der beruflichen Qualifizierung gaben sowie im sportlichen und musischen Bereich tätig wurden ${ }^{194}$. Wachsende Schwierigkeiten mit Vichy-Offiziellen oder regimetreuen Jugendgruppen und Verbindungen zur Résistance führten schließlich im Januar 1944 zur erzwungenen Auflösung der Compagnons. Relativ unbehelligt überdauerte die - nicht nur katholische - Jugendherbergsbewegung diese Zeit, obwohl die Mehrheit der ajistes ${ }^{195}$ sich offen auf die Politik Léo Lagranges berief, gegen Teile des konservativen Klerus die Gemeinschaft beider Geschlechter sowie den Laizismus in ihren Reihen verfocht und im Widerspruch zur Regierungsdoktrin eine rassistische Gesinnung ablehnte. In Ermangelung der notwendigen materiellen Mittel

191 Zitiert nach Cacérès, ebenda, S. 101. Skeptisch gegenüber Lagranges „staatsfernem“ Anspruch: Cross, Vacations, S. $611 \mathrm{f}$.

192 Zur Kultur und Kulturpolitik im Etat Français vgl. Rioux (Dir.), La vie culturelle; Added, Le théâtre; zur Schulpolitik die Beiträge von Martin und Handourtzel, in: Les Cahiers de l'Animation, No. 49-50, S. $87 \mathrm{ff}$.

193 So Cacérès, Histoire, S. 121; vgl. auch Les Cahiers de l'Animation, No. 49-50, insbesondere die Einführung von Gallaud, S. 6; zum Gesamtkomplex Giolitto, Jeunesse; Gay-Lescot, Sport; Halls, Les jeunes.

194 Vgl. hierzu Cacérès, ebenda, S. 125 ff.; die Beiträge von Gruiziat, Dupouey, Despinette und Aubert, in: Les Cahiers de l'Animation, No. 49-50, S. $37 \mathrm{ff}$.

195 Abgeleitet von „a.j.“, der Abkürzung für „auberges de la jeunesse“. 
verlegten sich die nichtkonfessionellen, politisch links ausgerichteten Camarades de la route et des Auberges françaises de la jeunesse, wie sie sich seit 1941 in der unbesetzten Zone nannten, zunehmend auf die Abhaltung von Studienzirkeln und kulturellen Unternehmungen. Der Einfluß Jean Gionos auf einen Teil des ajisme war immer noch groß ${ }^{196}$, trug aber auch ideologisch-moralische Spannungen in seine Reihen, als sich spätestens 1943 die Frage des Widerstands gegen die Deutschen und ihre französischen Helfershelfer stellte und konsequente Pazifisten entschlossenen Antifaschisten gegenüberstanden ${ }^{197}$. Während sich insgesamt die konfessionell geprägten Jugendund Erwachsenenbildungsorganisationen weitaus größerer Toleranz und Förderung seitens des Etat Français erfreuen konnten als diejenigen, die sich auf linksrepublikanische Traditionen beriefen und in den Jahren der Volksfront besonders unterstützt worden waren, so scheint es doch, als habe die Entourage des greisen Marschalls zumindest bis 1942 die laizistischen Jugendgruppen, im Unterschied zu den erwachsenenorientierten, „volkskulturell“ ambitionierten Vereinigungen, gewähren lassen ${ }^{198}$. Zum Ausdruck kam die regierungsoffizielle „exaltation quasi-permanente des vertus de la jeunesse ${ }^{\text {“99 }}$ nicht zuletzt in der Einrichtung eines Staatssekretariats für Jugendfragen, das in Vichy an die Stelle des Staatssekretariats für Sport und Freizeit trat. In dieser neuen Behörde war Jean-Charles Moreau zunächst als stellvertretender Bürochef, seit 1942 als Abteilungsleiter für die Förderung und das zu diesem Zweck eingeführte Zulassungsverfahren der Jugendverbände zuständig ${ }^{200} .1945$ ging Moreau nach Baden-Baden, um in Schmittleins Direction de l'Education Publique die Jugendabteilung der Unterdirektion Sports et Jeunesse zu übernehmen.

Offizielle Organisationen des Vichy-Regimes waren die Chantiers de la jeunesse, Arbeitsdienstlager mit Pfadfindercharakter für Wehrpflichtige, die ebenso wie die Ecoles des cadres, Ausbildungsstätten für die künftige Elite der „neuen Ordnung“, unmittelbar nach der militärischen Niederlage Frankreichs in der unbesetzten Zone entstanden, um die Heerscharen demobilisierter und desorientierter Jugendlicher in staatlich kontrollierbare Bahnen zu lenken. Nach der Einführung des Zwangsarbeitsdienstes für junge Franzosen in Deutschland (STO) im Frühjahr 1943 stellten die Chantiers das Hauptreservoir für die so Gepreßten dar. Einige ihrer Verantwortlichen gingen in den

196 Giono gehörte nach dem Krieg in Frankreich zu den umstrittenen Schriftstellern. 1939 hatte ihn sein kompromißloser Pazifismus zunächst ins Gefāngnis gebracht, dann kam er seinem Gestellungsbefehl doch nach. Seine ambivalente Haltung in den Jahren 1940-44 gegenüber Pétains „Nationaler Revolution“ brachte ihn nach der Befreiung zunächst auf die schwarze Liste, bevor er Anfang der 50er Jahre eine gewisse Rehabilitierung erfuhr; vgl. de Mendelssohn, Der Geist, S. 122 ff.

197 Hierzu Cacérès, Histoire, S. 129 ff.; die Beitrāge von Heller-Goldenberg, Paillet, Auclaire, Rocher und Porte in: Les Cahiers de l'Animation, No. 49-50, S. $67 \mathrm{ff}$.

198 Hierauf verweist Gallaud, ebenda, S. $5 f$.

199 Ebenda, S. 6.

200 UUber Grundzüge seiner Tătigkeit im Vichy-Staatssekretariat berichtet Moreau in: Les Cahiers de l'Animation, No. 49-50, S. 35 f. Auskunft gab er ferner in einem ausführlichen Interview, das eine Gruppe Freiburger Doktoranden am 9./10.5.1988 mit ihm führen konnte und dessen Tonbandprotokoll dem Verf. dankenswerterweise von Reinhard Grohnert zugänglich gemacht wurde. Bei dieser Gelegenheit stellte Moreau ausdrücklich einen Zusammenhang zwischen seinen Erfahrungen der Jahre 1940-44 und der Jugendpolitik der französischen Militärregierung in Deutschland nach 1945 her: „La promotion de l'idée de pluralisme“ sei das Leitmotiv gewesen. 
Untergrund und trugen nach Kriegsende zum neuen Aufschwung der éducation populaire in Frankreich bei ${ }^{201}$. Auch unter den Ecoles des cadres befand sich eine, die dem Regime zunehmend entglitt und schließlich nach der Besetzung Restfrankreichs im November 1942 zum Widerstand überging: die von Uriage in der Dauphiné202. Hier hatte sich auf Initiative eines aristokratischen, pétaintreuen Offiziers ein kleiner Kreis von Persönlichkeiten - unter ihnen der spātere „Le Monde“-Gründer Beuve-Méry zusammengefunden, die aus unterschiedlichen politisch-ideologischen Lagern kamen, wobei die Strömung des sozial engagierten, teilweise kirchenkritischen Katholizismus zunächst überwog. Aus dem anfänglich regimekonformen Ziel der Uriage-Equipe, Jugendgruppenleiter auszubilden und in Schulungskursen für junge Führungskräfte einen neuen Lebensstil unter den künftigen Eliten Frankreichs zu propagieren, um so die „nationale Revolution“ zu fördern, entwickelte sich mit der Zeit ein doppeltes Spiel. Unter dem Einfluß von Philosophen wie Mounier und Intellektuellen aus dem Umkreis der „Nonkonformisten der 30er Jahre ${ }^{\text {"203 }}$ fand man zu einem revolutionären Humanismus christlicher oder personalistischer Prägung und entfremdete sich auch politisch den staatlichen Doktrinen und Institutionen. Kurzlehrgänge für aktive Mitglieder katholischer Jugendgruppen, wie der Scouts, der JEC und JOC, wurden veranstaltet; aber auch längerfristige Studienzyklen, in denen mit neuartigen Lehrmethoden experimentiert wurde, gehörten zum Programm. Neben dieser offiziellen Seite entstanden Verbindungen zum Exil und begannen - als Konsequenz des Patriotismus, der von Anbeginn den esprit d'Uriage prägte - Vorbereitungen auf den bewaffneten Widerstand, dem sich nach der gewaltsamen Auflösung der Kaderschule Ende 1942 einige Mitglieder anschlossen. Von hier führt eine direkte Linie zur Gründung von Peuple et Culture (PEC) an der Jahreswende 1944/45. Die Lebenswege der Gründungsmitglieder illustrieren, in welch hohem Maße die geschilderten Hauptkomponenten einer eigenständigen éducation populaire in die neue Organisation einflossen und damit die Nachkriegsentwicklung prägten.

\section{Die Gründer von Peuple et Culture}

Der eigentliche Initiator von PEC war Joffre Dumazedier, ein Philologe, dessen Agrégation durch den Kriegsbeginn vereitelt wurde ${ }^{204}$. Während seines Studiums, in dessen Verlauf ihn vor allem die Philosophie Alains (d.i. Emile Chartier) prägte ${ }^{205}$, schloß er sich nacheinander einer sozialistischen, einer kommunistischen, schließlich einer unabhängigen linken Studentengruppe an. So unerläßlich ihm zeitlebens die Existenz politischer Parteien für eine demokratische Staatsordnung erschien, wurden ihm doch die Grenzen ihrer Wirkungsmöglichkeiten gerade im kulturellen Sektor deutlich. Um

${ }^{201}$ Vgl. Cacérès, Histoire, S. $121 \mathrm{ff}$, ferner den Erlebnisbericht Duchaines, in: Les Cahiers de l'Animation, No. 49-50, S. $51 \mathrm{ff}$.

${ }^{202}$ Zum Folgenden grundlegend: Comte, Utopie combattante; zusammenfassend ders., L'esprit; Cacérès, ebenda, S. $131 \mathrm{ff}$.; Les Cahiers de l'Animation, No. 49-50, S. $147 \mathrm{ff}$.; zur weltanschaulich-philosophischen Ausrichtung der ursprünglichen Uriage-Equipe: Bitoun, Les hommes; Hellman, Mounier, S. $174 \mathrm{ff}$. und $183 \mathrm{ff}$.

${ }^{203}$ Vgl. hierzu Loubet del Bayle, Les non-conformistes.

${ }^{204}$ Zum Folgenden vgl. Dumazedier, in: Entretiens avec B. Cacérès et al., S. 26 ff.

${ }^{205}$ Zum intellektuellen Einfluß Alains auf die akademische Jugend der Zwischenkriegszeit vgl. Sirinelli, Génération intellectuelle; zusammenfassend ders., Les khâgneux. 
so mehr beeindruckte ihn die Jugendherbergsbewegung, die so sinnfällig die verbreitete antibürgerliche Gesinnung der jungen Leute zu verkörpern schien, sowohl ein inniges Verhältnis des Menschen zur Natur als auch solidarische zwischenmenschliche Beziehungen zu verwirklichen suchte und in diesem Geiste Angehörige der verschiedenen Klassen und Schichten zusammenbrachte. 1936 übernahm Dumazedier zunächst die Leitung der Jugendherberge in einem Pariser Arbeitervorort und wechselte dann an das von der Gewerkschaft CGT im selben Viertel eröffnete Collège de travail über. Nach Frankreichs Kapitulation im Sommer 1940 beauftragte ihn das Staatssekretariat für Jugendfragen mit der Führung eines Lagers für junge „entwurzelte“ Arbeitslose, bevor er von hier nach Uriage versetzt wurde. Über den Untergrund des Vercors gelangte er 1944 in die Erziehungskommission des Befreiungskomitees für die Region Isère ${ }^{206}$. Nach der Vertreibung der deutschen Besatzungsmacht beauftragte ihn die wiederhergestellte demokratische Regierung mit der Oberaufsicht über die Jugend und das Volksbildungswesen im Schulbezirk Grenoble. Hier gründete Dumazedier mit einigen Gesinnungsfreunden im Dezember 1944 Peuple et Culture, nachdem bereits wenige Monate zuvor ein Centre d'Education ouvrière an das örtliche Collège de travail der Volksfrontära angeknüpft hatte. Der Name Peuple et Culture geht im übrigen auf ein ebenfalls 1936 in Grenoble gegründetes Kulturzentrum zurück ${ }^{207}$. Als Hauptmotiv nennt Dumazedier rückblickend sein Bestreben zur Verminderung der sozialen, klassenbedingten Ungleichheit in kulturellen Belangen ${ }^{208}$. In diesem Sinne sollte PEC eine „dritte Kraft“ neben den gewerkschaftlichen und politischen Widerstandskräften gegen den Kapitalismus darstellen, „une force culturelle suffisamment puissante pour changer les mentalités“209. Die älteren Vorbilder der Volkshochschulen und Jugendherbergen standen ihm zwar vor Augen, doch war Dumazedier ehrgeizig genug, etwas Neues schaffen und eine wahre Volksbildungsbewegung ins Leben rufen zu wollen.

Die ersten Tätigkeiten von PEC in Grenoble und ihrer Filiale in Annecy ${ }^{210}$ umfaßten Studienzirkel, Vorträge, Diskussionen, Filmvorführungen, Ausstellungen und Theaterinszenierungen im Maison de la Culture. Volksbüchereien wurden eingerichtet und Lehrgānge für angehendes Personal der Erwachsenenschulung veranstaltet. Das Arbeiterbildungszentrum der CGT schloß sich schon bald der neuen Bewegung an. In ihm hatte Bénigno Cacérès sein Betätigungsfeld gefunden, ein enger Vertrauter Dumazediers, mit dem er schon in Uriage, dann im Untergrund über neue Formen der Erwachsenenbildung diskutiert hatte ${ }^{211}$. Cacérès, als Sohn spanischer Einwanderer im Arbeitermilieu von Toulouse aufgewachsen, war 1942 durch Vermittlung eines linkskatholischen Geistlichen nach Uriage gekommen, wo er noch vor der deutschen Besetzung der Freien Zone mit der Anlage eines versteckten Waffenlagers betraut wurde. Nach der gewaltsamen Auflösung der Ecole des cadres betätigte er sich als Ausbilder im Maquis, bevor er Mitte 1944 nach Uriage zurückkehrte. Hier war unterdessen ein Ausbildungslager für Kämpfer der verschiedenen Befreiungsarmee- und Parti-

206 Dies nach Cacérès, in: Entretiens avec B. Cacérès et al., S. 3.

207 Vgl. Peuple et Culture (Ed.), Peuple et Culture 1945-1965, S. 9.

208 Dumazedier, in: Entretiens avec B. Cacérès et al., S. 26.

209 Ebenda, S. 36.

$210 \mathrm{Vgl}$. hierzu Gabriel Monnet, in: ebenda, S. $76 \mathrm{f}$.

211 Zum Folgenden vgl. Cacérès, in: ebenda, S. 1 ff. 
saneneinheiten eingerichtet worden. Ende desselben Jahres holte ihn Dumazedier nach Grenoble, wo Cacérès den Leiter des Arbeiterbildungszentrums Paul Lengrand kennenlernte.

Lengrands Vita wiederum weist Parallelen zu der des etwas jüngeren Dumazedier auf $^{212}$. Am selben Pariser Elitegymnasium ausgebildet und ebenfalls von Alains Philosophie beeinflußt, dem kommunistischen Milieu, nicht aber der Partei verbunden und vom Sieg der Volksfront mitgerissen, studierte Lengrand Literatur und Sprachen, die er anschließend, nachdem der Kriegsausbruch seine Agrégation vereitelt hatte, als einfacher Gymnasiallehrer unterrichtete. Anders als Dumazedier, jedoch nicht atypisch für den Zeitgeist, sieht sich Lengrand rückblickend als „spekulativen Marxisten“, der Balzac und Stendhal den Verfassern des kommunistischen Manifests an die Seite stellte und sich für Marx hauptsächlich als Erben Goethes (!) interessierte. Deutschland war für ihn die große Entdeckung seines Lebens, nachdem er 1927 bei einem Aufenthalt im Nachbarland den „Reichtum der deutschen Seele“ kennen- und seine Philosophie, Musik und Malerei lieben gelernt hatte. Um so stärker traf ihn die nationalsozialistische Machtübernahme als „verstandes- und gefühlsmäßige Tragödie“213. Lengrand schloß sich nach dem militärischen Debakel und dem politischen Zusammenbruch der Dritten Republik nicht dem Widerstand an, sondern übte weiter seinen Lehrberuf aus. Der Zufall führte ihn im August 1944 ins befreite Grenoble, wo er Dumazedier traf und die Leitung des Arbeiterbildungszentrums übertragen bekam.

Die durch traumatische Erfahrungen getrübte, ambivalent gewordene Begeisterung für Deutschland verband Lengrand mit einem weiteren, dem für unseren Zusammenhang wichtigsten Mitglied von PEC, Joseph Rovan ${ }^{214}$. 1918 als Joseph Rosenthal in München geboren, erhielt der Sohn liberaler, akademisch gebildeter Großbürger, die früh von der jüdischen zur protestantischen Glaubensgemeinschaft übergetreten waren, seine Schulausbildung in Wien, Berlin und Paris. In die französische Hauptstadt emigrierte die Familie 1933, um nationalsozialistischer Verfolgung zu entgehen. Joseph studierte hier unter dem Einfluß Vermeils Germanistik, Geschichte und Politikwissenschaft. Schon als Gymnasiast von den publizistischen Arbeiten Gionos begeistert, pilgerte er, wie viele seiner Altersgenossen, 1938 in die Provence, um den persönlichen Kontakt zum Spiritus rector der laizistischen Jugendherbergsbewegung zu knüpfen. Der protestantisch Erzogene vollzog den Übertritt zum katholischen Bekenntnis, dessen sozial engagierten Vertretern er sich seit der regelmäßigen Lektüre von Mouniers Zeitschrift „Esprit“ verbunden fühlte. Schließlich erfaßte die kulturpolitische Euphorie der Volksfront auch den jungen Rovan. So eindeutig er und seine Freunde in der linkskatholischen oder anarchistisch geprägten Jugendherbergsbewegung gegen Nationalsozialismus und französischen Faschismus eingestellt waren, so unerläßlich erschien ihnen gleichzeitig „ein globaler Wandel“, „eine neue Welt“, die die bürgerlich-dekadente Gesellschaft der Dritten Republik ablösen sollte ${ }^{215}$. In dieser Verurteilung der politischen und sozialen Zustände Frankreichs trafen sich Kritiker von links und rechts, unter ihnen auch Reprāsentanten der neuen Macht um den greisen Marschall Pétain, deren autoritäres Regime von konservativen Kräften als Revan-

${ }^{212}$ Zum Folgenden vgl. Lengrand, in: ebenda, S. $48 \mathrm{ff}$.

213 Ebenda, S. 53.

${ }^{214}$ Zum Folgenden vgl. Rovan, in: ebenda, S. 92 ff.; Schulte, Le messager.

215 Rovan, ebenda, S. 94. 
che der katholischen Hierarchie an den Vertretern des Laizismus begrüßt wurde ${ }^{216}$. Die meisten konfessionellen Pfadfinder- und Jugendgruppen gingen jedoch mit der Zeit ins Lager der Résistance über, so auch Jeune France, eine Vereinigung zur „kulturellen Erneuerung“, gebildet von Persönlichkeiten, die, wie Rovan, von der „Esprit“Gruppe, von den katholischen Scouts oder aus der konfessionellen Jugendherbergsbewegung kamen ${ }^{217}$. In Lyon unterhielt Jeune France eine Ecole des cadres, an der Rovan nach der französischen Kapitulation in der Schulung künftiger Kulturvermittler tätig wurde. Die offizielle Schirmherrschaft durch den erzkonservativen, pétaintreuen Kardinal von Lyon ließ die Organisation nach außen unverdächtig erscheinen und ermöglichte es ihren Mitgliedern, heimliche Verbindungen zur Résistance zu knüpfen. Auch Rovan förderte Angehörige des Untergrunds und des Widerstands. Bei einem konspirativen Treffen in Paris ging er im Februar 1944 der Gestapo in die Falle, wurde eingesperrt, mißhandelt und schließlich im Juli ins Konzentrationslager Dachau verlegt, wo

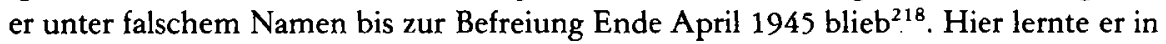
Edmond Michelet einen französischen Leidensgenossen kennen, der in der $Z$ wischenkriegszeit der katholischen Jugendbewegung angehört hatte, nach seiner Rückkehr aus Dachau 1945/46 Armeeminister de Gaulles wurde und Rovan zum Chef seines persönlichen Kabinetts berief. Auch dem Herausgeber von „Esprit“ begegnete Rovan nach seiner Haftentlassung wieder. Mounier emannte ihn zum Redaktionssekretär und erteilte ihm den Auftrag zu jenem Artikel, der im Oktober 1945 unter dem Titel "L'Allemagne de nos mérites" erschien und weithin bekannt wurde. Doch damit nicht genug: Politik und Journalismus schienen Rovans Arbeitskraft keineswegs zu erschöpfen; die Volksbildung kam als drittes Betätigungsfeld hinzu. Zwischenzeitlich hatten ehemalige Kollegen von Jeune France, Persönlichkeiten aus Kunst und Musik, Theater, Filmkritik und Verlagswesen, die Vereinigung Travail et Culture (TEC) gegründet, die in engem Einvernehmen mit kommunistischer Partei und Gewerkschaft Arbeitsund Kulturwelt einander näherzubringen suchte ${ }^{219}$. Sie hatten bereits zu PEC in Grenoble Kontakt aufgenommen und sich mit Dumazediers Team auf eine Assoziierung beider Gruppen geeinigt. Als Rovan aus Dachau zurückkehrte, boten ihm Freunde von TEC das Amt des Vizepräsidenten an. In dieser Eigenschaft wurde er gleichzeitig Mitglied im Führungsgremium von PEC und im Herbst 1945 Generalsekretär eines gemeinsamen Dokumentationszentrums in Paris.

\section{Das Programm von Peuple et Culture}

Die Prinzipien, nach denen PEC tätig zu werden gedachte, wurden 1945 formuliert und Anfang 1946 in einem „Manifest" veröffentlicht ${ }^{220}$. Seine Autoren beklagten zunächst die volks- und realitātsferne Bildungs- und Kulturkonzeption der Vorkriegsära, beschworen demgegenüber die katalytische Wirkung der Résistance und betonten deren klassenübergreifende, solidaritätsfördernde und gemeinschaftsbildende Funktion,

${ }_{216} \mathrm{Vgl}$. hierzu auch Duquesne, Les catholiques.

217 Vgl. Rovan, ebenda, S. 95. Schulte, Le messager, S. 325, nennt diese Gruppe Les Amitiés Chrétiennes; vgl. hierzu auch Chabrol, L'ambition.

${ }^{218}$ Vgl. Rovan, Erzählungen.

219 Vgl. Cacérès und Rovan, in: Entretiens avec B. Cacérès et al., S. 16 ff. bzw. 97; Cacérès, Histoire, S. $154 \mathrm{f}$.

${ }^{220}$ Peuple et Culture (Ed), Un peuple, une culture. 
die im Widerstand geschmiedete Einheit von Arbeitern, Ingenieuren, Offizieren, Intellektuellen und Künstlern ${ }^{21}$. Nicht nur überkommene bürgerliche Institutionen, wie die Universitäten, wurden der Kritik unterzogen, sondern auch die frühen Volksbildungsinitiativen, die als idealistische Ansätze wohlmeinender Intellektueller oder oft zu anspruchsvolle Bemühungen der gewerkschaftlichen Arbeiterbildung wenig Gnade fanden ${ }^{222}$. Das Hauptziel bestand nun darin, „Kultur“ und „Volk“ einander näher zu bringen. Doch was war damit gemeint? „Wir wollen keine aristokratische oder bürgerliche Kultur, die auf ein neues Publikum ausgedehnt wird. Volkskultur (culture populaire) kann nur die sein, die einem ganzen Volk gemeinsam ist: den Intellektuellen, den Führungskräften (cadres), der breiten Bevölkerung (masses). Sie kann nicht zugeteilt werden. Man muß sie gemeinsam erleben, um sie zu erschaffen. ${ }^{\text {"223 }}$ Doch damit an definitorischen Gemeinplätzen nicht genug: „Die wahre Kultur erwāchst aus dem Leben und kehrt zum Leben zurück. [...] Weder Literatur noch Wissenschaft noch das Recht (alleine) machen eine Kultur aus. Diese Bereiche steuern nur einen Teilaspekt bei.“ Schließlich kamen, in Abwandlung, auch Marx und Engels zu Wort: „Wahre Kultur dient nicht nur dazu, die Welt zu deuten, sondern sie zu verändern.“224

Dreierlei setzte nach Meinung der Manifest-Autoren die Förderung einer „wahren“, „lebendigen“ Kultur voraus: einen bestimmten Menschentypus, adäquate Methoden zur Wissensvermittlung und Persönlichkeitsbildung sowie den Aufbau einer organisatorischen Infrastruktur. Hinsichtlich der erstgenannten Prämisse postulierten sie einen „neuen Humanismus“, der zwangsläufig revolutionär sein müsse ${ }^{225}$. Zur Begründung dieser Forderung, die sowohl an die in Uriage als auch in Résistancekreisen entwickelten Thesen anknüpfte, wurden - teils offen deklariert, teils unausgesprochen - Bruchstücke aus dem CEuvre von Marx und Nietzsche, Ortega y Gasset und Giono zusammengesetzt: Betrachtungen über die Ära und den Aufstand der Massen bei gleichzeitiger Bejahung der Existenz von Eliten, über die Bedeutung der modernen Technik und Naturwissenschaft, von Jugend und Nonkonformismus, Sportlichkeit und Naturverbundenheit, aber auch Ordnung und Disziplin. Alle diese Phänomene zeugten nach Ansicht der PEC-Gründer von einem optimistischen Menschenbild, vom Glauben an die Menschheit. Schließlich vertraten sie - unter Berufung auf Marx und Nietzsche - die Maxime, daß Wissen und Macht, Erkenntnis und Handlung eine enge Verbindung eingehen müßten ${ }^{26}$. Hinsichtlich der zweiten Prämisse wurde die Einführung einer „revolutionären Technik“ in die Erwachsenenbildung anvisiert ${ }^{227}$. Mit der herkömmlichen Schulpädagogik sei in diesem Bereich nichts anzufangen, da es nicht um die Vermittlung von Wissensstoff, sondern um die Entwicklung individueller Fähigkeiten und Anlagen gehe. Dafür müsse ein "geistiges Trainingsprogramm (entraînement mental)“ erarbeitet werden. Als Zielsetzung formulierte dieser Teil des Manifests: „Es gilt, den Geschmack umzuerziehen, die herkömmlichen Ausdrucksfor-

\footnotetext{
221 Vgl. ebenda, S. 5ff.

222 Vgl. ebenda, S. $8 f$.

223 Ebenda, S. 10.

224 Ebenda, S. 11.

225 Zum Folgenden vgl. ebenda, S. $13 \mathrm{ff}$.

$226 \mathrm{Vgl}$ ebenda, S. 17.

227 Vgl. ebenda, S. $19 \mathrm{ff}$.
} 
men zu bekämpfen, das Gespür (sensibilité) zu entwickeln und, vor allem, in jedermann die Kreativität (pouvoir de création) freizusetzen. “228 Schließlich, befand der dritte und letzte Abschnitt, werfe das Volksbildungswesen große organisatorische Probleme auf. Unter Anknüpfung an Projekte der Volksfrontära wurden Institutionen für den Freizeitbereich, die Arbeiterschulung und das volkstümliche Kulturleben konzipiert $^{229}$. Einrichtungen, wie sie im Ausland, in der Sowjetunion, den Vereinigten Staaten und Schweden, bereits bestanden, galten als Vorbilder ${ }^{230}$. Am Ende ihres Grundsatzprogramms folgten die PEC-Initiatoren dem „Kommunistischen Manifest“ von 1848 , indem sie den revolutionären Willen zur Durchsetzung einer klassenlosen Gesellschaft und Kultur beschworen ${ }^{231}$. Im selben Atemzug räumten sie ein, daß ein solches Fernziel illusionslos, mit viel Geduld anzustreben sei: „Die Veränderung der Verhaltensweisen (moours) und der gesellschaftlichen Verhältnisse (rapports sociaux) ist möglicherweise die schwierigste aller Revolutionen." 232

Dieses ebenso emphatisch formulierte wie eklektisch komponierte Dokument ${ }^{233}$ spiegelt die Heterogenität der jungen Organisation wider und ist beredter Ausdruck ideologischer Ambivalenzen, die in der Zeit nach dem deutsch-französischen Waffenstillstand vom Frühsommer 1940 die Übergänge zwischen Kollaboration und Résistance fließend gestaltet hatten. Mancher Parteigänger der Pétainschen Révolution nationale konnte in seinem Traum vom „neuen Menschen“, seiner Forderung nach neuen Erziehungsmethoden und seinen Vorstellungen von den zugrundeliegenden Prinzipien mit Postulaten des „revolutionären Humanismus“ konform gehen ${ }^{234}$. Als gemeinsamen Nenner der PEC-Gründer wies das Manifest schließlich ihre globale Vision, den revolutionären Impetus und ihren missionarischen Eifer auf dem Weg zu einer alle Bevölkerungskreise erreichenden "Volkskultur“ aus.

Wie das Jakobinertum 150 Jahre zuvor, so machte auch die von der Libération beflügelte Aufbruchsstimmung in der Volksbildungsbewegung nicht an den eigenen Landesgrenzen halt. Ihre Verkünder ergriffen die Gelegenheit eines siegreich beendeten Krieges, um ihre Ideen über den Rhein zu exportieren. Erleichtert wurde diese Möglichkeit, als Joseph Rovan Ende 1947 die PEC-Zentrale verließ, nachdem ihn ein Angehöriger der französischen Militärregierung in Freiburg für eine Tätigkeit im besetzten Südwestdeutschland gewonnen hatte ${ }^{239}$. Als Leiter des Bureau de l'éducation populaire in Schmittleins Erziehungs- und Kulturbehörde wirkte Rovan vier Jahre

228 Ebenda, S. 22.

229 Vgl. ebenda, S. 24f. Die Rede ist von den Clubs de loisirs populaires, wie sie 1936 von Léo Lagrange entworfen, doch nicht realisiert worden waren, von Centres d'enseignement pratique und Foyers de culture populaire.

230 Vgl. ebenda, S. 27.

231 Vgl. ebenda, S. 29.

232 Ebenda, S. 30.

233 Dies bringt auch der Fragesteller Jean-Pierre Saez in den Entretiens avec B. Cacérès et al., S. 9 f. und $56 \mathrm{f}$., kritisch zur Sprache.

234 Vgl. am Beispiel einer kollaborationistischen Jugendgruppe Yagil, „Jeunesse de France".

235 Vgl. Schulte, Le messager, S. 330. Rovan war bereits vor seiner Tätigkeit in Baden-Baden mit dem Abteilungsleiter für Jugendfragen in Schmittleins DEP, Moreau, bekannt. Dieser hatte ihn Ende 1945 in Paris aufgesucht und um seine Mitwirkung gebeten. Noch als stellvertretender Generalsekretär von PEC korrespondierte Rovan mit Moreau im Frühjahr 1947 u. a. wegen der Versorgung der französischen Zone mit PEC-Material; in: AOFA, AC 269,3 und 271,3 . 
lang getreu seiner Überzeugung, daß das Volksbildungswesen in Frankreich so lange nicht gedeihen könne, als das in Deutschland nicht wieder funktionstüchtig sei ${ }^{236}$. Wiederholt lud er in dieser Zeit die führenden Vertreter von PEC und TEC in die französische Besatzungszone ein, um Lehrgänge und Vortragskurse zur Ausbildung deutscher wie französischer Kulturvermittler abzuhalten ${ }^{237}$. Auf diese Weise eröffnete sich der Organisation ein „Markt“, auf dem die eigenen Grundsätze zur Anwendung gebracht und erprobt werden konnten.

${ }^{236}$ So Cacérès über Rovan, in: Entretiens avec B. Cacérès et al., S. 15.

${ }^{237}$ Vgl. Rovan, in: ebenda, S. 105. 